Performance

No.1790

August 2021

\title{
Why working from home will stick
}

Jose Maria Barrero

Nicholas Bloom

Steven J. Davis 


\begin{abstract}
COVID-19 drove a mass social experiment in working from home (WFH). We survey more than 30,000 Americans over multiple waves to investigate whether WFH will stick, and why. Our data say that 20 percent of full workdays will be supplied from home after the pandemic ends, compared with just 5 percent before. We develop evidence on five reasons for this large shift: better-than-expected WFH experiences, new investments in physical and human capital that enable WFH, greatly diminished stigma associated with WFH, lingering concerns about crowds and contagion risks, and a pandemic-driven surge in technological innovations that support WFH. We also use our survey data to project three consequences: First, employees will enjoy large benefits from greater remote work, especially those with higher earnings. Second, the shift to WFH will directly reduce spending in major city centers by at least 5-10 percent relative to the prepandemic situation. Third, our data on employer plans and the relative productivity of WFH imply a 5 percent productivity boost in the post-pandemic economy due to re-optimized working arrangements. Only one-fifth of this productivity gain will show up in conventional productivity measures, because they do not capture the time savings from less commuting.
\end{abstract}

Key words: Covid-19, USA, productivity, technological innovations

We thank Stanford University, the University of Chicago Booth School of Business, Asociacion Mexicana de Cultura A.C., the Stanford Institute for Human-Centered Artificial Intelligence, the W.E. Upjohn Institute for Employment Research, and Toulouse Network for Information Technology for financial support. We are grateful to comments from presentations at the AEA, Berkeley, CUNY, HAI, Hoover Institution, ITAM, LSE, Maryland, Munich, Rice, Northwestern, Ridge, Princeton, Stanford, Wharton, The World Bank, and ZEW-Mannheim. We thank Corinne Stephenson for help generating our WFH media data.

Jose Maria Barrero, Instituto Tecnologico Autonomo de Mexico. Nicholas Bloom, Stanford University and Centre for Economic Performance, London School of Economics. Steven J. Davis, Booth School of Business, University of Chicago.

This paper was produced as part of the Centre's Growth Programme. The Centre for Economic Performance is financed by the Economic and Social Research Council.

Published by

Centre for Economic Performance

London School of Economics and Political Science

Houghton Street

London WC2A 2AE

All rights reserved. No part of this publication may be reproduced, stored in a retrieval system or transmitted in any form or by any means without the prior permission in writing of the publisher nor be issued to the public or circulated in any form other than that in which it is published.

Requests for permission to reproduce any article or part of the Working Paper should be sent to the editor at the above address.

C J.M. Barrero, N. Bloom and S.J. Davis, submitted 2021. 


\section{Introduction}

COVID-19 triggered a mass social experiment in working from home (WFH). Americans, for example, supplied roughly half of paid workhours from home between April and December 2020, as compared to five percent before the pandemic. ${ }^{1}$ This seismic shift in working arrangements has attracted no shortage of opinions about whether WFH will stick. Netflix CEO Reed Hastings offers one view: "I don't see any positives. Not being able to get together in person, particularly internationally, is a pure negative." At the other end of the spectrum, Rite Aid CEO Heyward Donigan reports, "We have adapted to work-from-home unbelievably well... We've learned that we can work remote, and we can now hire and manage a company remotely." Apple CEO Tim Cook expresses an intermediate view, "In all candor, it's not like being together physically....[But] I don't believe that we'll return to the way we were because we've found that there are some things that actually work really well virtually." 2

We develop systematic evidence about whether WFH will stick, why, and some of the economic and societal implications. To do so, we exploit multiple waves of data from an original cross-sectional survey of our design - the Survey of Working Arrangements and Attitudes (SWAA). We have fielded the survey about once a month since May 2020, thus far collecting over 30,000 responses from working-age Americans. We ask about working arrangements during the pandemic, personal experiences with WFH, worker preferences and employer plans about the extent of WFH after the pandemic ends, attitudes about contagion risks and vaccination, and much more. ${ }^{3}$ Our survey data track the incidence of working from home and provide insights into how a persistent shift to WFH will affect worker well-being, productivity, commuting time, spending near business premises, and sales tax revenues in large cities. Our data also throw new light on desires to work remotely, the stigma associated with WFH, lingering concerns about working or commuting in close proximity to others, and more. To supplement our analysis of the survey data, we draw on informal conversations with dozens of U.S. business executives.

\footnotetext{
1 Drawing on several independently conducted surveys, Barrero et al. (2020), Bick et al. (2020), Brynjolfsson et al. (2020), and Ozimek (2020) find that about half of paid workhours were supplied from home in the Spring of 2020. Figure 1 below shows the WFH share from May 2020 to March 2021.

${ }^{2}$ The quotations are from Cutter (2020).

${ }^{3}$ Our data are available to other researchers at www.WFHresearch.com. We continue to field the SWAA and update the website about once a month.
} 
Forty percent of SWAA respondents aged 20-64 worked from home in May 2020, while 26 percent worked on business premises and just over a third did not work. Figure 1 shows, accordingly, the share of full paid working days worked home exceeded 60 percent in May. The incidence of WFH fell steadily from May to late October, before rebounding in November as the pandemic worsened and government authorities re-imposed some restrictions on commercial and social activities. As of March 2021, employees supplied about 45 percent of paid labor services from home. In comparison, workers supplied only 5 percent of full workdays from home in 20172018 (BLS, 2018). The share WFH three or more days per week rose from $0.75 \%$ in 1980 to $2.4 \%$ in 2010 (Mateyka et al., 2012) and 4.0\% in 2018 (BLS, 2018). ${ }^{4}$ Thus, the huge COVID-induced shift to WFH follows a slow, modest rise over the previous forty years.

The SWAA puts the following question to employed respondents: "After COVID, in 2022 and later, how often is your employer planning for you to work from home?" According to the responses, employers plan for workers to supply $21.3(0.2)$ percent of full workdays from home after the pandemic ends. Roughly speaking, WFH is feasible for half of employees, and the typical plan for that half involves two workdays per week at home. Business leaders often mention concerns around workplace culture, motivation, and innovation as important reasons to bring workers onsite three or more days per week. Many business people also tell us they see net benefits to WFH one or two days per week, consistent with survey evidence in Altig et al. (2020a).

Most workers welcome the option to work remotely one or more days per week, according to our data. SWAA respondents are willing to accept pay cuts of 7 percent, on average, for the option to work from home two or three days per week after the pandemic. While the preferred frequency of WFH varies greatly among individuals, desires to work from home part of the week are pervasive across groups defined by age, education, gender, earnings, and family circumstances. The actual incidence of WFH rises steeply with education and earnings.

Our projection for the extent of WFH in the post-pandemic economy is four times its prepandemic level, but only two-fifths of its average level during the pandemic. Thus, our data also imply a partial reversal of the massive COVID-induced surge in WFH. The reversal mostly involves adjustments on the intensive margin, whereby many persons WFH five days per week

\footnotetext{
${ }^{4}$ The pre-pandemic wage premium or discount associated with WFH varies greatly with observable worker characteristics, occupation, and WFH intensity (Pabilonia and Vernon, 2021). Average wages associated with WFH evolved from a large discount in 1980, conditional on controls, to a modest premium by 2014 (White, 2019).
} 
during the pandemic will shift to two or three days per week after it ends. Data collected from a similar survey for the United Kingdom show very similar patterns (Taneja et al., 2021).

As to why working from home will partly stick after the pandemic, we develop several pieces of evidence and analysis. First, COVID-19 necessitated costly experimentation with WFH by millions of individuals and organizations. Basic decision theory predicts that compulsory experimentation with a new technology has persistent effects after the forcing event ends, as decision makers re-optimize working arrangements in light of newly gleaned information. In line with this prediction, many SWAA respondents report better-than-expected WFH experiences and higher productivity at home. They also report better-than-expected WFH experiences on average, pointing to excessive pessimism about WFH before the pandemic. ${ }^{5}$ In addition, the pandemic created the conditions for coordinated experiments with WFH in networks comprised of firms, customers and suppliers, yielding lessons and know-how that were hard to acquire beforehand. In sum, the pandemic swept aside inertial forces related to experimentation costs, biased expectations, and coordination within networks that had previously inhibited remote work.

Second, the average worker has invested 15 hours of time and \$561 dollars in home equipment to facilitate WFH, according to our survey data. The dollar value of these investments amounts to 0.7 percent of annual GDP. In addition, the pandemic prompted firms and other organizations to improve back-end systems and equipment that support working from home. As a result of these pandemic-driven investments, both workers and firms are now better positioned to work from home effectively.

Third, the pandemic has altered attitudes in ways that support a shift to WFH. Two-thirds of SWAA respondents report improved perceptions about WFH among some, most or all "people you know" since the start of the pandemic, while less than seven percent report any deterioration. In addition, when asked for their views on social distancing after a vaccine becomes "widely available," only 28 percent of respondents say they will fully return to pre-COVID activities. The rest say they will remain wary of crowded elevators, subway travel, indoor restaurant dining, and ride sharing. Lingering fears of proximity to others will prop up the demand for WFH.

Fourth, the share of new U.S. patent applications that advance WFH technologies more than doubled from January to September 2020, greatly surpassing its previous peak (Bloom, Davis and Zhestkova, 2021). This development will raise the quality and efficiency of remote work over time,

\footnotetext{
${ }^{5}$ Ozimek (2020) obtains a similar result in a survey of U.S. hiring managers.
} 
reinforcing a shift to WFH well after the pandemic ends. The surge in patents that advance WFH technologies fits nicely with theories that stress market size effects on the direction of technical change (e.g., Acemoglu, 2002). COVID-19 also spurred innovations in the regulatory sphere, easing the way for a large rise in virtual consultations by doctors, nurse practitioners, clinical psychologists and social workers (Bajowalla et al., 2020 and Webster, 2020). If regulations remain supportive of virtual consultations, WFH will be more practical for healthcare professionals.

Turning to societal consequences, our data imply large worker benefits of a post-pandemic shift to WFH, mainly due to reduced commuting time. The benefits will accrue disproportionately to the highly educated and well paid. Indeed, the gap between employer plans regarding WFH and employee desires is small for highly paid workers, but it becomes wider and wider as we look down the earnings distribution. WFH is also more valuable to highly paid workers, because they have longer commutes and a greater opportunity cost per unit time.

The shift to WFH will also have highly uneven geographic effects, diminishing the fortunes of cities like San Francisco with high rates of inward commuting. Using our data on working arrangements, commuting patterns, and worker spending near employer premises, we estimate that the post-pandemic shift to WFH will lower expenditures on meals, entertainment, personal services, and shopping in major cities by 5 to 10 percent of pre-pandemic overall spending. Conversely, the shift to WFH will commercially benefit other communities, as outward commuting drops. Evidence for these effects during the pandemic in De Fraja et al. (2021) aligns well with our evidence of projected effects after the pandemic.

Finally, many persons report higher productivity when WFH during the pandemic than on business premises before the pandemic. Using our survey data on self-assessed productivity effects of WFH, employer plans about who will work from home in the post-pandemic economy, commuting times and more, we estimate that the re-optimization over working arrangements in the post-pandemic economy will boost productivity by 4.6 percent relative to the pre-pandemic situation. The main source of this productivity boost is the savings in commuting time afforded by more WFH. This gain is missed by conventional productivity measures. Indeed, as conventionally measured, we project a productivity boost of only 1.0 percent in the post-pandemic economy.

Our study relates to a rapidly growing literature on WFH. First, regarding productivity effects, Bloom et al. (2015) find that WFH brings a 13\% average productivity gain in randomized control trials of Chinese call-center workers. Nearly a third of the gain reflects more calls per minute, and 
the rest is due to fewer breaks. Similarly, Emanuel and Harrington (2021) report that WFH raises productivity $8 \%$ in a natural experiment with call-center workers at a large US firm. However, they also find negative selection of employees into WFH. The adoption of a work-from-anywhere approach yielded a $4 \%$ productivity gain in a natural experiment involving U.S. Patent Office workers (Choudhury et al., 2021). Similarly, Angelici and Profeta (2020) find that granting employees some flexibility over when and where to work raises productivity in a field experiment at a large Italian firm. Kunn et al. (2020) report lower performance among elite chess players when competing from home during the pandemic, perhaps because the home environment is less conducive to peak performance in cognitively demanding tasks.

A second strand of research considers the impact of WFH on employees. In a field experiment involving persons seeking call-center jobs, Mas and Pallais (2017) find that applicants will accept an 8 percent wage cut, on average, for the option to work from home in a full-time job. However, WFH conditions during the pandemic have been far from ideal due to children at home and shared working spaces, reducing family satisfaction (Möhring et al., 2020). Examining data for thousands of firms, DeFilippis et al. (2020) find that WFH involves more (but shorter) meetings per day, more email, and longer workdays. This second strand is part of a broader literature on alternative working arrangements and work-life balance (e.g., Bloom et al., 2009 and Mas and Pallais, 2020).

Finally, much recent research examines the extent and incidence of WFH during the COVID pandemic and the outcomes associated with WFH. See, for example, Adams-Prassle et al. (2020), Barrero et al. (2020b), Bartik et al. (2020), Bick et al. (2020), Brynjolfsson et al. (2020), Mongey et al. (2020) and Ozimek (2020). Davis et al. (2021), Favilukis et al. (2020), Pagano et al. (2020) and Papanikolaou and Schmidt (2020) study the relationship between firm-level stock returns during the COVID-19 pandemic and the capacity of their employees to work from home. Behrens et al. (2021) offer a general equilibrium analysis of WFH and its consequences. Like us, they stress that the effects of a shift to WFH are highly uneven across people and locations.

The next section provides more information about our survey. Section 3 quantifies WFH before, during, and after the COVID-19 pandemic. Section 4 explains why the COVID-induced shift to WFH will partly stick, and it offers several pieces of evidence on the mechanisms in play. Section 5 considers broader societal consequences of a persistent shift to WFH. Section 6 offers concluding remarks. 


\section{The Survey of Working Arrangements and Attitudes}

Since May 2020, we have run monthly waves of the Survey of Working Arrangements and Attitudes (SWAA). We design the survey instrument and pay two commercial survey providers, QuestionPro and Inc-Query, to recruit respondents and field surveys over the internet. Each survey includes 40 to 55 questions on demographics, working arrangements, earnings, commuting, spending near employer premises, expectations and experiences related to WFH, perceptions, and more. ${ }^{6}$ Figure A.1 displays two key SWAA questions - one about the respondent's WFH experience during the pandemic, and another about employer plans regarding WFH after the pandemic. We provide more information about individual questions below. ${ }^{7}$

Thus far, the SWAA went to field in ten waves, as follows: 21-25 May 2020, 30 June to 9 July (July wave), 21-28 August, 29 September to 2 October (September), 28 October to 3 November (October), 17-20 November, 12-28 December, 19-27 January 2021, 26-28 February, and 16-22 March. We ran two parallel surveys in August, collecting 2,500 responses from each survey provider and obtaining similar results for each August sample. We used a single provider for all other waves, collecting 5,000 responses apiece in December and January, 3,250 in February, and 2,500 responses apiece in the other waves. Median survey completion time (after dropping "speeders") ranges from 3 minutes, 10 seconds in the May wave to 10 minutes, 55 seconds in the December 2020 wave. We treat our data as repeated cross sections, although we cannot preclude the possibility that a given respondent appears in multiple waves.

Our target survey population is U.S. residents, 20-64 years old, who earned at least $\$ 20,000$ in 2019. Given these parameters, our survey providers recruit respondents from lists of verified persons supplied by leading market research aggregators, who gather potential respondents from multiple sources. One reason to draw from multiple sources is that the form of respondent compensation depends on where and how they are recruited for online surveys. Some respondents receive airline miles in exchange for survey participation, for instance, while others receive cash or credits that unlock valuable features of internet games. No respondents sign up specifically for our survey.

\footnotetext{
${ }^{6}$ We do not collect personally identifiable information, do not contact respondents directly, and have no way to re-contact them.

${ }^{7}$ We set forth all SWAA questions in Barrero, Bloom and Davis (2021).
} 
Prescott et al. (2016), Starr et al. (2020) and Bick and Blandin (2021) provide validation exercises and useful discussions of these sorts of online surveys. We adopt many of their practices to enhance data quality. For example, we drop persons who complete the survey in less than 2 minutes in May, less than 3 minutes in the July to November 2020 waves, and less than 5 minutes in the December 2020 to March 2021 waves. Given the nature and number of our survey questions, these "speeders" are unlikely to supply carefully considered responses. Dropping speeders cuts the sample by about 20 percent.

We seek a sample that is broadly representative of our target population. To that end, we reweight the raw survey data (again, after dropping speeders) to match the joint distribution of persons over age-sex-education-earnings categories in Current Population Survey (CPS) data from 2010 to $2019 .{ }^{8}$ Figure 2 shows marginal distributions of the raw survey responses, the reweighted responses, and CPS data over age, sex, education, and earnings categories. The raw data over represent persons with high earnings and high education, but the reweighted distributions match CPS data in each of these dimensions. Both raw and reweighted SWAA data are distributed similarly to the CPS data for the other variables in Figure 2, including those that are not part of our reweighting scheme. Still, our reweighted data may be selected in other respects that correlate with outcomes of interest. For example, internet survey participants might spend more time online and differ from non-participants in their WFH experiences and attitudes. We cannot rule out this possibility. Given near universal penetration of broadband internet, smartphones, and similar devices in 2020, we see this concern as less worrisome today than 10 or 15 years ago.

Table A.1 reports summary statistics for the reweighted sample. The modal respondent is a man, 40 to 50 years old with one to three years of college, who earned $\$ 40$ to $\$ 50$ thousand in 2019. Our core sample has 28,597 observations after dropping "speeders" and cleaning up inconsistent responses. Some variables have fewer observations, because they derive from questions not posed in all survey waves. Before the July wave, for example, we did not ask about employer plans regarding WFH after the pandemic. In addition, certain questions go only to persons WFH as of the survey date or at some point during the pandemic.

\footnotetext{
${ }^{8}$ We separately reweight the SWAA data for each survey provider, pooling over waves for a given provider.
} 


\section{Working Arrangements before, during, and after COVID-19}

\section{a. The extent of working from home before and during the Pandemic}

We measure the extent of WFH before the pandemic using American Time Use Survey data for about 10,000 wage and salary workers in 2017 and 2018, as detailed in Appendix A. To estimate employment status and working arrangements during the pandemic, we draw on the SWAA, which includes the following question in the May through October waves:

Currently (this week) what is your working status?

- $\quad$ Working on my business premises

- Working from home

- Still employed and paid, but not working

- Unemployed

- Not working and not looking for work

In November, we switched to a three-question structure that yields more granular data on the extent of WFH. The first question elicits the respondent's current work status:

Currently (this week) what is your work status?

- Working, whether on business premises or working from home

- Still employed and paid, but not working

- Unemployed, looking for work

- Unemployed, awaiting recall to my old job

- Not working, and not looking for work

For those who work, we then ask: How many full days are you working this week (whether at home or on business premises)? Response options are $1,2, \ldots, 5+$ days. The third question asks where work happens: You have indicated that you are working this week. How many full paid working days are you working from home this week? Response options are: None, all my paid working days were on business premises and separate options for 1,2, 3, 4 and 5+ full paid days WFH. Eighty-five percent of responses to these questions imply either full-time work on business premises or full-time work from home. We classify someone as WFH if full workdays at home account for at least 66 percent of all paid workdays.

We draw on responses to these questions to provide information about work status during the pandemic. In May 2020, when stay-at-home orders covered most of the country (Coibion et al., 2020), 40 percent of respondents worked from home, while only 26 percent worked on business 
premises and 34 percent were not working. In March 2021, however, 31 percent worked mainly from home and 43 percent worked mainly on business premises. ${ }^{9}$ Our data also show the partial recovery in labor market conditions, with the share of responses classified under "not working" dropping from 34 to 27 percent between May 2020 and March 2021.

Figure 1 summarizes the extent of WFH before and during the pandemic. ${ }^{10} \mathrm{WFH}$ during the pandemic dwarfs the extent in 2017-18. Across ten survey waves from May 2020 to March 2021, an average of 48.6 percent of all paid working days were provided from home, about 10 times the pre-pandemic share. WFH peaked in May at 61 percent of paid working days and fell back to 43 percent in late October, before climbing back to 51 percent in November. Since August, the SWAA also asks, "During the COVID-19 pandemic have you at any point worked primarily from home, for example, due to lockdowns or because it was unsafe or otherwise not possible to work on business premises?" Nearly 56 percent of respondents answer "yes" to this question.

\section{b. Who works from home?}

Table 1 considers how the incidence of WFH varies across groups in the SWAA data. As before, we treat respondents in the November and subsequent waves as mainly WFH if they supplied at least 66 percent of full workdays from home during the survey week. The share of persons mainly WFH rises steeply with education during the period from May 2020 to March 2021, consistent with evidence for April and May in Bick, Blandin and Mertens (2020) and Brynjolfsson et al. (2020). The share of SWAA respondents mainly WFH ranges from 10 percent for those who did not finish high school to 50 percent of those with a graduate degree. WFH

\footnotetext{
${ }^{9}$ A natural question is how our figures compare to Current Population Survey (CPS) data, which show $25 \%$ of employed persons 20-64 years old WFH in December 2020. See https://www.bls.gov/cps/effectsof-the-coronavirus-covid-19-pandemic.htm\#data. This CPS figure excludes persons "whose telework was unrelated to the pandemic, such as those who worked entirely from home before the pandemic." Judging from 2018 ATUS data, this exclusion lowers the reported WFH share in CPS data by 4-5 percentage points. In addition, the SWAA excludes persons who earned less than $\$ 20,000$ in 2019 . Thus, the SWAA population excludes low-wage, part-time workers who tend to be concentrated in retail and service sector jobs that involve face-to-face interactions and little scope for WFH.

${ }^{10}$ We count persons "Still employed and paid, but not working" as Not Working. We count employed persons as Working from Home, if they worked at least $66 \%$ of full workdays from home. In computing the WFH shares for the May-October waves, we assume persons classify themselves as WFH if they work at least $66 \%$ of full workdays from home, and we impute the share of paid workdays performed at home in November and December to the earlier months, conditional on classification as Working from Home or Working on Business Premises. In practice, $85 \%$ of employed respondents in November and December report working zero or all full workdays at home, and the WFH shares are not very sensitive to alternative thresholds for mainly WFH.
} 
propensity also rises steeply with earnings: It is more than twice as high among those earning at least $\$ 150$ thousand in 2019 as among those earning \$20-50 thousand. WFH is slightly less prevalent among men than women. It varies little by age, except for a notable drop among persons 50-64. The incidence of WFH is somewhat higher in service-producing sectors, households with children, and Democratic-leaning states. ${ }^{11}$

Table 2 reports the results of regressing an indicator for mainly WFH in the survey week on observables. All specifications include survey wave fixed effects and some include age-bin and industry effects, as indicated. We scale the continuous independent variables (years of education, log earnings, internet quality, Joe Biden's November 2020 vote share in the respondent's state) to mean zero and unit standard deviation. ${ }^{12}$ Education and earnings are the strongest marginal predictors of WFH during the pandemic. For example, a unit standard deviation increase in education involves a 6-9 percentage point increase in the likelihood of mainly WFH during the survey week, conditional on other observables. The conditional likelihood of mainly WFH is 8-9 percentage points higher for a unit standard deviation increase in earnings. These education and earnings effects are highly statistically significant. The conditional likelihood of mainly WFH also shows increases with Joe Biden's vote share, increases with internet quality, and is lower for men than women, but the coefficients are smaller than for earnings and education. In contrast, the coefficients on children under 18 in the household and their interaction with gender are statistically insignificant and often small in the Table 2 regressions. While much of the narrative surrounding the economic impact of the pandemic has focused on industry differences, controlling for industry has little impact on the pattern of results reported in Table 2.

\section{c. How much working from home after the pandemic?}

To what extent will the huge shift to WFH persist after the pandemic ends? To throw some light on this issue, we pose the following question to SWAA respondents:

After COVID, in 2022 and later, how often is your employer planning for you to work full days at home?

\footnotetext{
${ }^{11}$ We classify states according to the Cook Political Report's Partisan Voting Index, which uses data from the 2012 and 2016 presidential elections and is published at https://cookpolitical.com/state-pvis. While the Cook Index designates New Hampshire, Pennsylvania and Wisconsin as "EVEN," we treat them as "Blue" based on Joe Biden's wins in these states in the 2020 presidential election.

${ }^{12}$ Our survey elicits data on earnings, education, and internet quality for discrete categories to which we assign numerical values. For example, we set schooling to 10 for persons who did not finish high school, 12 to those who finished high school education but did not obtain additional schooling, and so on.
} 
- Never

- About once or twice per month

- 1,2, 3, 4, or 5+ days per week [separate options for each]

- My employer has not discussed this matter with me or announced a policy about it

- I have no employer

Before the August wave, the question specified "After COVID in 2021..." instead of 2022.

Responses to this question provide a basis for projecting the percent of full workdays to be provided from home after the pandemic ends. In constructing our projection, we drop persons who have no employer in the survey week. We assign zeros to "Never" and "About once or twice per month," 20 percent for 1 full day per week WFH, 40 percent for 2 full days, and so on. We also assign zeros to "My employer has not discussed this matter with me or announced a policy about it" on the view that employers are unlikely to discuss the matter with workers in jobs for which WFH is impractical or infeasible.

Implementing these calculations using SWAA data for March 2021, employer plans imply that WFH will account for 22.2 (1.0) of all workdays in the post-pandemic economy. When averaging over survey waves from July 2020 to March 2021, the figure is $21.3(0.2)$ percent, which is about four times the pre-pandemic WFH share in ATUS data. In the March 2021 wave, employers plan for 31.7 (1.3) percent of their employees to work from home at least one full day per week after the pandemic. Comparing plans for the post-pandemic economy to the actual March 2021 outcomes, 43 percent of the anticipated drop in WFH is due to persons who expect to shift from 5+ to fewer days per week WFH. This large role for intensive-margin adjustments aligns with what we hear from most business managers. By and large, they want employees on premises three or more days per week to support innovation, employee motivation, and company culture. They regard physical interactions on premises as essential but think three or four days per week onsite is sufficient. Many business leaders also see it as essential to coordinate employee days and times on premises to ensure overlap on the worksite.

When asked directly, employers also say they plan much more WFH after the pandemic ends than before it struck. For example, a Conference Board survey of mostly larger firms conducted in September 2020 says that 24 percent of employees will be mainly WFH " 1 year after 
the pandemic subsides," as compared to 6 percent "before COVID-19."13 Altig et al. (2020a, 2021) ask business executives about WFH plans in the Survey of Business Uncertainty (SBU), a broad sample of American companies fielded by the Federal Reserve Bank of Atlanta. ${ }^{14}$ The SBU question design is very similar to the SWAA question, facilitating a comparison. As of May 2020, firms in the SBU project that 18 percent of full workdays will be performed at home in the postpandemic economy. As of February 2021, the SBU-based projection is 15 percent.

There are several possible reasons why the SWAA yields a larger WFH projection than the SBU. First, by virtue of its focus on persons 20-64 who earned at least $\$ 20,000$ in 2019, the SWAA excludes many low-wage and part-time jobs that are unsuitable for WFH (e.g., staff at fast-food restaurants). These jobs account for a modest share of aggregate labor compensation but a sizable share of total employment. Second, as discussed in Section 2, the SWAA data may over represent persons who are more comfortable with online interactions and more likely to work from home. Third, the SBU does not cover government jobs, which may offer greater-than-average scope for WFH. Finally, the SBU sample is broadly representative of private activity across industries and regions, but it under-represents younger firms. Thus, insofar as WFH is more common at younger firms (within industries), the SBU is likely to understate the projected extent of WFH. We lack the data needed to fully reconcile SWAA and SBU projections for the post-pandemic WFH share. Nevertheless, it is reassuring that multiple surveys of workers and employers support the hypothesis that WFH will be 3-4 times as common after the pandemic ends than before 2020.

Returning to the SWAA data, Table 3 tabulates employer plans for the extent of WFH after the pandemic. WFH plans by age, sex, education, earnings and so on vary similarly to the actual incidence of WFH during the pandemic. In Table A.10b, we re-estimated the regression specification in Column (7) of Table 2 using the post-pandemic plans for WFH in place of actual WFH. Employer plans imply that the post-pandemic share of full workdays provided from home will rise with worker education and, especially, with earnings - both unconditionally and conditional on the other observables considered in Table 2.

\footnotetext{
${ }^{13}$ See Chart 1 in Steemers et al. (2020). We obtain 24 percent by assigning a WFH value of 0 to firms who say less than $10 \%$ of their employees will mainly work remotely after the pandemic, a value of 15 to those who say 10-20 percent, a value of 30 to those who say 20-40 percent, and a value of 40 to those who say 40 percent or more.

${ }^{14}$ Altig et al. (2020b) describe the Survey of Business Uncertainty in detail.
} 


\section{d. How much would people like to work from home?}

The SWAA includes the following question: "After COVID, in 2022 and later, how often would you like to have paid workdays at home?" Response options are "Never," "About once or twice per month," and separate options for 1, 2, 3, 4 and 5+ days per week. Figure 3 summarizes the response distribution among all respondents and for the 64 percent that can work from home. Nearly two-thirds of respondents and nearly 80 percent of those able to work from home want to do so at least one day per week. About 30 percent want to work from home all week. Roughly half of employees who can work from home in their current job (and nearly forty percent of all respondents) want to split the workweek between home and employer premises. Table 3 shows that preferences for a split workweek are remarkably prevalent: Men and women, old and young, high and low earners, college graduates and non-college workers, and those in "blue" and "red" states prefer WFH 40 to 50 percent of working days. Conditional on other observables, men desire fewer days WFH (Table A.10). Among those with children under 12 and at least some college, women are much more likely than men to prefer WFH five days a week (Figure A.3).

We also elicit information about how much workers like or dislike WFH in pay-equivalent terms. ${ }^{15}$ First, we ask, "After COVID, in 2022 and later, how would you feel about working from home 2 or 3 days a week?" Response options are "Positive: I would view it as a benefit or extra pay, "Neutral," and "Negative: I would view it as a cost or a pay cut." If the response is "Positive" or "Negative," we follow up with:

How much of a pay raise [cut] (as a percent of your current pay) would you value as much as the option to work from home 2 or 3 days a week?

- Less than a 5\% pay raise [cut]

- A 5 to $10 \%$ pay raise [cut]

- A 10 to $15 \%$ pay raise [cut]

- $A 15$ to $25 \%$ pay raise [cut]

- $\quad$ A 25 to $35 \%$ pay raise [cut]

\footnotetext{
${ }^{15}$ The discussion in the text and Figure 4 focus on data from the September 2020 to February 2021 waves, which elicited workers' value of working from home with the question described in the text. In the August 2020 survey wave, the second part of the question involved less granular quantitative options. In the May and July 2020 waves, we used a one-question approach. Results are similar for these other survey waves. In March 2021 we began testing a different question design to elicit worker's value of working from home. See Barrero, Bloom, and Davis (2021) for details.
} 
- More than a 35\% pay raise.

As summarized in Figure 4, nearly two-thirds of respondents value the option to work from home 2 or 3 days per week. More than half see it as worth a pay raise of 5 percent or more, and nearly one in five see it as worth a pay raise of 15 percent or more. In sum, the vast majority of SWAA respondents would like to work from home at least one day per week, and more than half express a willingness to accept a sizable pay cut for the option to work from home part of the week.

\section{The Shift to Working from Home: Mechanisms}

Evidence in the previous section points to a large and persistent shift to WFH, triggered by the COVID-19 pandemic. This section aims to explain why WFH will be more prevalent after the pandemic ends than before it struck, and to offer some insight into what drives the future extent of WFH. We start with a theoretical framework that identifies potential mechanisms at work in a persistent shift to WFH. We then present evidence on the mechanisms.

\section{a. A theoretical framework}

Firms have two available production technologies: a traditional technology $(T)$ that involves little or no remote work by staff, and an alternative technology $(R)$ with heavy reliance on remote work. Since high levels of WFH were uncommon before COVID-19, we focus on firms that use technology $T$ before the pandemic. Firms know their payoff distributions under $T$, but we allow for imperfect, possibly biased, knowledge of payoff distributions under $R$. Each period, firm $i$ chooses an action $a_{i}$ in $\{T, R, M\}$ to maximize the discounted sum of current plus expected future payoffs, where $M$ stands for mothballing operations at a per-period payoff of zero.

When operating technology $T$ in period $t$, the firm's current payoff $x_{i t}$ is distributed $F_{i}^{T}\left(x ; p_{t}\right)$, where $p_{t}=\{$ normal, pandemic $\}$ and $F_{i}^{T}(x$; normal $) \leq F_{i}^{T}(x$; pandemic $)$ for all $x .^{16}$ That is, a pandemic worsens the payoff distribution $F^{T}$ in the sense of first-order stochastic dominance. Here, $p$ captures the negative effects of social distancing and government orders on the viability of the traditional technology. The first time a firm uses technology $R$, it incurs incur a one-time $\operatorname{cost} C_{i}$ for upfront investments to enable remote work. Aside from $C_{i}$, the firm's current payoff is distributed $F_{i}^{R}\left(x ; \gamma_{t}\right)$ under $R$, where $\gamma_{t}$ is the activity share of firms operating $R$ in $t$, and higher values of $\gamma$ improve $F_{i}^{R}$ in the first-order stochastic dominance sense. Thus, $\int x d F_{i}^{R}\left(x ; \gamma_{t}\right)-$

\footnotetext{
${ }^{16}$ If $p_{t}$ is stochastic, we assume that it obeys a first-order Markov process.
} 
$\int x d F_{i}^{T}\left(x ; p_{t}\right)$ rises with $\gamma$ for given $p$, and there is a strategic complementarity across firms in the choice of production technology. As a real-world example, WFH becomes more viable for law firms when more of their clients work remotely.

Consider the implications of a pandemic that arrives at $t=1$ when firms know $F_{i}^{R}\left(x ; \gamma_{t}\right)$. Let $V_{i t}^{a}\left(p_{t}, \gamma_{t}, \mathbb{C}\right) \equiv V_{i t}^{a}$ denote the value function associated with action $a_{i t}$ under the optimal continuation policy, where $\mathbb{C}$ is an indicator variable that equals 1 if the firm previously operated $R$. Among firms that choose $a_{i t}=T$ for $t \leq 0$, a sufficient condition for switching to $R$ at $t=1$ is $\int x d F_{i}^{R}\left(x ; \gamma_{0}\right)-C_{i}+V_{i 1}^{R}>\int x d F_{i}^{T}(x ;$ pandemic $)+V_{i 1}^{T}$. The equilibrium share of switchers is governed by the weaker requirements that switchers satisfy $\int x d F_{i}^{R}\left(x ; \gamma_{1}\right)-C_{i}+V_{i 1}^{R}>$ $\int x d F_{i}^{T}$ ( $x$; pandemic $)+V_{i 1}^{T}$. That is, by raising the activity share of the $R$ technology to $\gamma_{1}>\gamma_{0}$, the pandemic makes $R$ more attractive for each firm. Thus, the pandemic's negative impact on payoffs under $T$ and the pandemic-induced increase in remote work both drive the adoption of technology $R$ when the pandemic hits.

Some firms that switch when the pandemic strikes will stick to $R$ after the pandemic ends in period $t=n \cdot{ }^{17}$ Here as well, there are two effects: Having incurred the switching costs, some firms find it optimal to continue with $R$ even if all other firms switch back to $T$; for these firms, $\int x d F_{i}^{R}\left(x ; \gamma_{0}\right)+V_{i n}^{R}>\int x d F_{i}^{T}(x ;$ normal $)+V_{i n}^{T}$. Other firms stick to $R$ after the pandemic ends because $\int x d F_{i}^{R}\left(x ; \gamma_{n}\right)+V_{i n}^{R}>\int x d F_{i}^{T}(x ;$ normal $)+V_{i n}^{T}$, although $\int x d F_{i}^{R}\left(x ; \gamma_{0}\right)+V_{i n}^{R}<$ $\int x d F_{i}^{T}(x ;$ normal $)+V_{i n}^{T}$. Thus, the strategic complementarity in choice of production technologies amplifies the pandemic-induced switching response at $t=1$ and raises the activity share of firms that operate $R$ after the pandemic ends. ${ }^{18}$

Now consider the situation where firms have imperfect knowledge of their payoff distributions when operating $R$. Let $\tilde{F}_{i t}^{R}\left(x ; \gamma_{t}, \boldsymbol{\theta}_{i t}\right)$ denote the perceived payoff distribution at $t$ under technology $R$, where $\boldsymbol{\theta}_{i t}$ is a vector that summarizes information and beliefs about the payoff distribution at $t$.

\footnotetext{
${ }^{17}$ This claim requires that some firms be close to the switching margin before the pandemic hits.

18 This conclusion does not rest on coordination failures of the sort that can arise with strategic complementarities. However, a pandemic could drive a persistent rise in $\gamma$ even with no switching costs, if strategic complementarities are strong enough to generate multiple equilibria. See Cooper and John (1988) for an analysis of shock amplification and coordination failures in the presence of strategic complementarities in payoff functions.
} 
When a firm operates $R$, its realized payoffs may lead it to update $\boldsymbol{\theta}_{i t}$ and revise $\tilde{F}_{i t}^{R} .{ }^{19}$ As before, the arrival of a pandemic at $t=1$ causes some firms to switch from $a_{i t}=T$ for $t \leq 0$ to $a_{i 1}=R$. Firms with sufficiently favorable payoffs under $R$ from $t=1,2, \ldots n$ will stick with $R$ after the pandemic ends. Here, stickiness in technology switching does not require $C_{i}>0$ or other explicit switching costs. Instead, payoff observations under $R$ lead to revisions in $\tilde{F}_{i t}^{R}$ that, for some firms, are favorable enough for them to prefer $R$ to $T$ after the pandemic ends. That is, some firms discover that remote work is so productive they decide to stick with the practice post-pandemic.

While not necessary for stickiness, overly pessimistic priors about the viability of remote work leads to more stickiness. To see this point, start with the case of unbiased priors. Suppose, for example, that firms know the $F^{R}$ distributions up to a mean parameter $\mu_{i}$ that differs among firms. They also believe, correctly, that the $\mu_{i}$ are distributed $G(\mu, \sigma)$, where $\mu$ is the mean of the $\mu_{i}$ and $\sigma$ is the standard deviation. Pandemic-induced experimentation and learning leads some firms to discover they have high values of $\mu_{i}$, so they stick with $R$ after the pandemic ends. We refer to this outcome as a tail effect of experimentation. Now consider the case with overly pessimistic priors. In particular, suppose firms believe the $\mu_{i}$ are distributed $G(\tilde{\mu}, \sigma)$, where $\tilde{\mu}<\mu$ and the true distribution remains $G(\mu, \sigma)$. In this case, pandemic-induced experimentation and learning yields even more stickiness through a bias elimination effect.

As we remarked in the introduction, the pandemic created conditions for coordinated experiments with WFH in networks comprised of firms, customers and suppliers, yielding lessons and know-how that were hard to acquire beforehand. Specifically, firms may find it much easier to learn about $F_{i}^{R}(x ; \gamma=$ high $)$ when other firms also seek to learn about technology $R$ - a strategic complementarity in experimentation. Conversely, firms may find it infeasible to learn much about $F_{i}^{R}(x ; \gamma=$ high $)$ when operating in an economy where the traditional technology dominates. This observation helps understand why many firms may have had highly imperfect, possibly biased, views about the viability of WFH before the pandemic.

\section{b. COVID-driven experimentation altered views and plans about working from home}

What has pandemic-driven experimentation revealed about WFH? To help address this question, we put the following to SWAA respondents who worked from home during COVID:

\footnotetext{
${ }^{19}$ See Rothschild (1974) on how to formulate $\boldsymbol{\theta}$ in the case of a Bayesian agent with a prior over support points on a multinomial distribution.
} 
Compared to your expectations before COVID (in 2019) how has working from home turned out for you?

- Hugely better -- I am 20+\% more productive than expected

- Substantially better -- I am to 10\% to 19\% more productive than I expected

- Better -- I am 1\% to 9\% more productive than I expected

- About the same

- Worse -- I am 1\% to 9\% less productive than I expected

- Substantially worse -- I am to $10 \%$ to $19 \%$ less productive than I expected

- Hugely worse -- I am 20\%+ less productive than I expected

Figure 5 shows the distribution of responses, and Table A.2 tabulates mean responses by group. Nearly six in ten respondents say they are more productive than expected when WFH; only 14 percent say they are less productive than expected. On average, productivity when WFH during the pandemic is $7.1(0.1)$ percent higher than expected. These results are consistent with evidence from a survey of hiring managers in Ozimek (2020).

Recall that WFH productivity surprises can contribute to a persistent increase in remote work in two ways. First, there is a tail effect: some employees (and their employers) learn that WFH works especially well for them - enough so to stick with it after the pandemic. In terms of our theoretical framework, they learn that their $\mu_{i}$ values are in the upper part of $G(\mu, \sigma)$. This effect arises even with unbiased priors. Second, there is a bias elimination effect: Figure 5 says priors about WFH productivity were negatively biased before the pandemic.

Do workers and employers adjust their future plans in light of what they learn by experimenting with WFH during the pandemic? Yes, according to our survey data. Figure 6 shows that employer plans for the extent of WFH after the pandemic rise with WFH productivity surprises during the pandemic. Among persons who report that WFH turned out "Hugely better" than expected, their employers plan an extra 1.5 days per week of WFH in the post-pandemic economy compared with those who report "Hugely worse," and an extra 0.8 days per week of WFH compared with those who report "About the same." Worker desires for WFH after the pandemic also rise with their WFH productivity surprises during the pandemic. Respondents who report that WFH turned out "Hugely better" than expected desire, on average, 1.6 more days WFH per week after the pandemic than those who report "Hugely worse." Thus, the information revealed by 
forced experimentation alters plans and desires for the extent of WFH after the forcing event ends, in line with the prediction of our theoretical framework. ${ }^{20}$

\section{c. Pandemic-induced investments improve WFH capabilities}

The sudden shift to WFH in reaction to COVID-19 spurred workers and firms to invest in physical, human, and organizational capital that, in turn, improves WFH capabilities. Millions learned to use teleconferencing software and remote collaboration tools or acquired desks, chairs, microphones, better computers, etc., to improve WFH capabilities. Because they are durable, these investments contribute to the persistence of the pandemic-induced shift to WFH.

To quantify some of these physical and human capital investments, we use responses to two questions put to SWAA respondents who worked from home during the pandemic:

- How many hours have you invested in learning how to work from home effectively (e.g., learning how to use video-conferencing software) and creating a suitable space to work?

- How much money have you and your employer invested in equipment or infrastructure to help you work from home effectively -- computers, internet connection, furniture, etc.? ${ }^{21}$

The average respondent in the July 2020 to January 2021 survey waves reported 15.0 (0.2) hours and $\$ 561$ (9) in expenditures devoted to at-home investments that enable WFH. Valuing time at the respondent's wage, the mean dollar-equivalent investment is $\$ 1,444$ (30) among those with WFH experience. Summing over respondents (assigning zero to those who did not work from home), dollar-equivalent investments to enable WFH amount to 1.2 percent of their aggregate 2019 labor income. Multiplying this figure by 0.59, the ratio of aggregate employee compensation to GDP in 2019Q4, we estimate that aggregate pandemic-induced investments to enable WFH equal $0.7 \%$ of annual GDP.

We believe this figure substantially understates pandemic-induced investments to enable and support WFH, because our survey data do not capture investments on business premises and in the cloud. These include the acquisition and installation of new software and security systems for a

\footnotetext{
${ }^{20}$ People also exhibit persistent behavioral responses to temporary forcing events in other settings. For example, Larcom, Rauch, and Willems (2017) find that many commuters permanently altered their travel routes after a London Underground strike forced them to experiment with alternatives. The permanent route-altering response is stronger among commuters who live in areas where the Undergound map is more distorted. This pattern suggests that the behavioral response is at least partly due to information revealed by forced experimentation.

${ }^{21}$ For those who report positive investments, we also ask, What percentage of this expenditure has been reimbursed or paid by your employer? The average response to this question is 61 percent.
} 
remote-work environment, new servers and other hardware, and new systems to manage remote workers. While we cannot quantify these sorts of investments, data from the National Income and Product Accounts suggest they are sizable. As in nearly all recessions, business investment fell in 2020, but purchases of IT equipment, computers, and peripherals actually rose (Eberly, 2020). By our calculations, U.S. Private Fixed Investment in Information Processing Equipment and Software rose more than 10 percent as a share of GDP from 3.8 percent in 2019 to 4.2 percent in 2020 Q2 and Q3. Over the same period, all other components of U.S. Gross Private Domestic Business Investment fell 16 percent as a share of GDP from 9.6 to 8.1 percent. ${ }^{22}$

\section{d. Stigma associated with WFH diminished during COVID}

Before COVID-19, working from home was often seen as a form of shirking. In line with this view, a pre-COVID analysis by Emanuel and Harrington (2021) found productivity to be 12\% lower among persons who selected into $\mathrm{WFH} .{ }^{23}$ Because the pandemic compelled tens of millions to work from home for months on end, it seems plausible that COVID-19 precipitated a favorable shift in attitudes regarding WFH. In turn, that type of attitude shift could prompt employers to offer greater opportunities for remote work and leave employees more inclined to work remotely. To get at this potential attitude shift, the SWAA includes the following question: ${ }^{24}$

Since the COVID pandemic began, how have perceptions about working from home (WFH) changed among people you know?

- Hugely improved -- the perception of WFH has improved among almost all (90-100\%) the people I know

- Substantially improved -- the perception of WFH has improved among most but not all of the people I know

\footnotetext{
${ }^{22}$ Calculations using data series A679RC1Q027SBEA, W987RC1Q027SBEA and GDP downloaded from FRED on 28 February 2021. A portion of home equipment expenditures reimbursed by employers and captured in SWAA data may also show up in NIPA data on business investment. However, unless the reimbursement is for equipment that enters into the employer's asset register and appears on its balance sheet, it is recorded as a business expense rather than business investment.

${ }^{23}$ To be clear, they find an $8 \%$ positive treatment effect of WFH - i.e., the same employee is more productive when WFH. However, those who selected into WFH were $12 \%$ less productive than others, conditional on work location.

${ }^{24}$ Early SWAA waves inserted the following sentence at the start of the question: "Before COVID-19, 'working from home' was sometimes seen as 'shirking from home.'" We randomized between question versions with and without this priming language in the December 2020 wave, obtaining nearly identical response patterns in each case. We opted for the version without priming language in later waves. Figure 5 and Table A.7 use responses from both versions and pool across all survey waves.
} 
- Slightly improved -- the perception of WFH has improved among some people I know but not most

- No change

- Slightly worsened -- the perception of WFH has worsened among some, but not most, people I know

- Substantially worsened -- the perception of WFH has worsened among most, but not all, people I know

- Hugely worsened -- the perception of WFH has worsened among almost all (90-100\%) the people I know

Two-thirds of SWAA respondents report improved perceptions of WFH among people they know. Less than 7 percent say perceptions have worsened. Figure 7 shows the full distribution of responses. Appendix Table A.4 additionally shows that perceptions of WFH improved more among persons with higher pay and more education. These persons were also more highly exposed to WFH during the pandemic (Tables 1 and 2), so it is perhaps unsurprising that WFH stigma fell away more sharply for them. Altogether, these results leave little doubt that the stigma associated with WFH diminished during the pandemic.

Our survey evidence also suggests that these attitude shifts will alter post-pandemic behavior. Specifically, Appendix Table A.7 shows that employer plans and employee desires for WFH after the pandemic are greater among persons who report larger improvements in perceptions about WFH among people they know. These results support the view that a COVID-induced shift in attitudes about WFH will contribute to the stickiness of WFH after the pandemic ends.

\section{e. Fears of mingling and proximity to others will linger}

Since the pandemic's early stages, the hope has been that a widespread deployment of COVID19 vaccines will lead to herd immunity and a safe return to a full range of social and commercial activities. The United States appears to have good prospects for eventual herd immunity as of April 2021 , given the approval of three high-efficacy vaccines and a mass vaccination campaign that is well underway. However, a successful vaccination campaign does not ensure that attitudes, habits and norms related to social mingling and proximity to others will revert to their pre-COVID states. The extent to which they do has profound implications for working arrangements, how and where people spend their incomes, and the types of businesses and communities that will thrive in the post-pandemic economy. 
To cast some light on how the pandemic affected attitudes about proximity to others, we begain posing the following question in the SWAA waves in July 2020:

If a COVID vaccine is discovered and made widely available, which of the following would best fit your views on social distancing?

- Complete return to pre-COVID activities

- Substantial return to pre-COVID activities, but I would still be wary of things like riding the subway or getting into a crowded elevator

- Partial return to pre-COVID activities, but I would be wary of many activities like eating out or using ride-share taxis

- No return to pre-COVID activities, as I will continue to social distance

Starting in the December 2020 wave, we made small modifications to this question to reflect developments in the discovery, approval, and availability of vaccines. ${ }^{25}$

Table 4 shows the response distribution. Only 28 percent of respondents anticipate a "complete return" to their pre-COVID activities. Another 34 percent anticipate a "substantial return" but will remain wary of riding the subway or a crowded elevator, and 24 percent say they will remain wary of eating out or using ride-share taxis. Yet another 14 percent say they will continue to social distance even after a vaccine is discovered and made widely available. ${ }^{26}$ Future actions may not fully align with survey responses, but these results caution against the view that a successful vaccine campaign will fully restore pre-pandemic behavioral and spending patterns. This conclusion also finds support in anecdotal reports of pandemic-induced changes in spending patterns (e.g., Mims 2020, Naughton 2020, Torry 2020, and Putzier 2021) and systematic evidence that COVID-19 is driving a large increase in the reallocation of jobs across firms (Barrero, Bloom, and Davis 2020b, and Barrero, Bloom, Davis, and Meyer 2021).

In the September, October, and November waves, we also asked why of respondents who do not foresee a full return to pre-COVID activities. Table A.6 reports the results. Eighty-five

\footnotetext{
${ }^{25}$ In December 2020, the question read "If a COVID vaccine is approved and made widely available" (emphasis added). In January and February 2021 we removed the reference to approval asking only about respondent attitudes "If a COVID vaccine becomes widely available..." In March 2021 as vaccine eligibility became imminently widespread we asked about attitudes "Once most of the population has been vaccinated against COVID" (emphasis in the original question). See Barrero, Bloom and Davis (2021) for the full questions.

${ }^{26}$ Table A.5 reports the share of persons who would return completely once a vaccine arrives by group. The share is notably higher among men, the highly educated, and those with earnings over $\$ 150,000$.
} 
percent express concerns about the efficacy, safety, or take-up of vaccines, which is consistent with other survey evidence (e.g., Hopkins 2020 and Tyson, Johnson, and Funk 2020). More than one-fifth say they are concerned about other diseases, and nearly one-fifth say they have "gotten used" to social distancing, e-commerce, and avoiding in-person goods and services.

\section{f. Pandemic-induced innovations will improve remote interactivity}

When remote work becomes a bigger share of all work, it strengthens the incentives to advance technologies that support WFH. This sentence recasts an old idea in a new context. Schmookler (1966) and Acemoglu (2002), among others, stress the role of market-size effects on the pace and direction of technical change. Acemoglu and Lin (2004) find that exogenous increases in (anticipated) market size stimulate the entry of new drugs that serve the larger market. Changes in relative market size also alter the direction of pharmaceutical innovations, according to their study. In a similar spirit, Kremer (2002) argues that small markets inhibit the development of cures for poorcountry diseases like malaria and tuberculosis.

Bloom, Davis, and Zhestkova (2021) investigate whether COVID-19 has stimulated innovations that support WFH. To do so, they examine the text content of U.S. patent applications from 2010 onwards, identifying the ones that advance technologies in support of video conferencing, telecommuting, remote interactivity, and working from home (collectively, WFH technologies). The share of new patent applications that advance WFH technologies more than doubles from January to September of 2020 by their assessment, greatly surpassing its previous peak, and following an upward trajectory since the onset of the pandemic. Their evidence suggests that COVID-19 is re-directing technical change in ways that will improve remote interactivity. By improving the quality and productivity of remote work, this re-direction of technical change will reinforce the shift to WFH even after the pandemic ends. Other research suggests that the extent of WFH is indeed responsive to innovations that facilitate remote work. In a study of 14 European countries from 2008 to 2016, Jerbashian and Vilalta-Bufi (2020) find that faster price declines for information and communication technologies (ICT) are associated with larger increases WFH, and that the effect is stronger for industries that rely more heavily on ICT.

\section{Economic and Societal Consequences}

The shift to WFH has important societal consequences. We use our survey data to develop evidence on consequences related to who benefits, commuting time, worker spending in city centers, and productivity gains from re-optimizing over working arrangements. Other studies delve 
into how WFH affects housing demand (Stanton and Tiwari, 2021), housing prices and rents (Ramani and Bloom, 2021), the division of labor within households (Alon et al. 2020a, and Del Boca et al. 2020), and residential electricity consumption (Cicala, 2020) - an incomplete list.

\section{a. WFH benefits will flow mainly to the well paid and highly educated}

Most SWAA respondents desire to work from home two or more days per week after the pandemic (Figure 3). Most also place high value on the option to work from home 2 or 3 days per week (Figure 4). Thus, many employees stand to benefit from higher levels of WFH in the postpandemic economy. We now develop evidence on the size and distribution of these benefits.

Table 3 reports information about employee desires and employer plans for WFH in the post-COVID economy. To compute the entries, we assign midpoint values to individual-level categorical responses and then compute means within groups using our usual sample weights. The average levels of desired WFH are high and similar across groups defined by age, sex, education, earnings, industry sector, and the presence of children. In contrast, employer plans for WFH in the post-pandemic economy rise steeply with education and earnings. These results suggest the benefits of the shift to WFH will flow mainly to the highly educated and well paid.

Figure 8 provides more granular evidence on how WFH desires and plans relate to earnings. Desires and plans are similar for the highly paid, namely those who earned $\$ 225,000$ or more in 2019. As we move down the earnings distribution, however, the gap between desires and plans becomes wider and wider. Among persons in the lowest three earnings groups in Figure 8 (corresponding to those earning less than $\$ 50,000$ in 2019), the average desired level of WFH is about 2.2 days per week, while the average plan is for only 0.8 days.

To quantify the benefits of WFH in the post-pandemic economy, we combine our data on employer plans with our data on how much employees value the option to WFH 2 or 3 days per week (Figure 5). We assign zero value to persons who are "Neutral" about WFH, 40 [-40] percent to those who value the option at "More than a 35\% pay raise [cut]," and interval midpoint values to the remaining responses. On average, employees value the option to work from home at $7.2 \%$ (0.1) of earnings by this measure, which is similar to the $8 \%$ estimate that Mas and Pallais (2017) derive from experimental data on job applications. Next, we adjust each respondent's "raw perk value" in light of his or her employer's plans for WFH in the post-pandemic economy. Specifically, we multiply the raw perk value by 0 , if the plan is to work from home "Never" or "About once or twice per month"; 1/2, if the plan is WFH "One day per week"; and 1, if the plan is for WFH 
multiple days per week. We refer to this adjusted raw perk value as the "value of planned postCOVID WFH."

Table 5 reports means by group for the raw perk values and the value of planned postCOVID WFH. The mean raw perk value ranges from around 5.6 percent of earnings for those who did not continue to post-secondary education to $9.5(0.1)$ percent for those with a graduate degree and 11.7 (0.2) percent for persons earning more than $\$ 150,000$. The raw perk value is somewhat higher for women than men and higher for persons with children in the household. It rises steeply with earnings. More residential space and nicer homes for high earners probably contribute to this positive relationship, but average one-way commute times also rise with earnings except at the very top end (Figure A.2). The average one-way commute time is less than 22 minutes for persons earning less than $\$ 30,000$ and about 44 minutes for those earning $\$ 150,000$ to $\$ 250,000$.

Turning to projected consequences, WFH will yield larger benefits (as a percent of earnings) for men, the college-educated, those with children, and persons with greater earnings. ${ }^{27}$ Again, the earnings relationship is very steep: The value of planned post-COVID WFH ranges from 1.7 (0.1) percent of earnings for persons earning less than $\$ 50,000$ in 2019 to $6.8(0.2)$ percent for those earning more than $\$ 150,000$. This steepness reflects two factors: First, higher earners place greater value on the option to WFH, as seen in the raw perk values. Second, planned WFH levels in the post-pandemic economy rise sharply with earnings, as seen in Figure 8 and Table 3. Of course, actual benefits are likely to be shared between workers and employers. So, one could restate our evidence as saying that the extra surplus created by the shift to WFH is greater for men, the highly educated, those with children and, especially, those with higher earnings. The division of this extra surplus between employer and employee depends on the structural characteristics of the labor market and the wage determination process.

Altogether, our evidence says that the persistent shift to WFH will yield benefits across a broad range of worker groups. The mean value of planned post-COVID WFH is positive for all groups in Table 5. The benefits are larger, and much larger on some dimensions, for groups that experienced less hardship in the labor market during the pandemic. ${ }^{28}$ They are especially large for the better educated and the highly paid.

\footnotetext{
${ }^{27}$ In unreported results, we obtain similar results when we value WFH using respondent commute times and hourly wages instead of using their reported willingness to pay for the option to WFH.

${ }^{28}$ See, for example, Adams-Prassl et al. (2020), Alon et al. (2020b), and Mongey et al. (2020) on the distribution of labor market outcomes during the pandemic.
} 


\section{b. A big savings in commuting time}

We start with some ballpark estimates of how the shift to WFH affects aggregate commuting time. According to the Current Population Survey, about 150 million Americans worked for pay as of December 2020. According to the 2018 American Community Survey, workers spent an average 54 minutes per day commuting to and from work before the pandemic. ${ }^{29}$ Recall that WFH rose from about $5 \%$ of workdays before COVID to $50 \%$ during the pandemic. Putting the pieces together, the COVID-induced shift to WFH yielded an aggregate reduction in commuting time of $(0.5$ minus 0.05$)(150$ million $)(54 / 60$ hours $)=61$ million hours per work day during the pandemic. That amounts to $(5 / 7)(30)(61)=1.3$ billion hours per month, or more than 15 billion hours from mid-March 2020 to March 2021. Since our survey data say that 20 (not 50) percent of full workdays will be supplied from home after the pandemic ends, our ballpark calculations imply that the COVID-induced shift to WFH will reduce aggregate commuting time by about 435 million hours per month in the post-pandemic economy. Below, we draw out some implications of this reduction in commuting time for worker spending in city centers and labor productivity.

Drawing on SWAA data, Barrero et al. (2020a) find that Americans devote about $35 \%$ of their savings in commuting time to their primary jobs and about $60 \%$ to work activities of all sorts, including household chores and childcare. The allocation of time savings is broadly similar for men and women and across groups defined by race and ethnicity, but it differs markedly by education group and between persons with and without children at home. Their findings align well with American Time Use Survey data on how time allocations relate to WFH in 2017 and 2018, as analyzed in Pabilonia and Vernon (2020).

\section{c. Inward commuting drops will cut spending in major city centers}

The shift to WFH raises serious concerns about the future of urban centers, especially those characterized by high inward commuting rates and large employment shares in jobs that are suitable for remote work. One concern involves the reduction of worker spending near employer premises, which often cluster in city centers (Althoff et al. 2020, and Liu and Su 2020). We use our survey data to project the impact of the shift to WFH on spending in selected urban areas. To do so, we exploit SWAA questions about employer location and pre-COVID worker spending on food, shopping and entertainment near workplaces.

${ }^{29}$ This figure reflects employed persons 16 and older who did not work from home. 
Figure 9 displays two patterns in the data that relate to the effect of more WFH on worker spending in city centers. The left panel summarizes the relationship between weekly worker expenditures near their workplaces before COVID-19 and population density near those workplaces. The message is clear: worker spending near employer premises rises with population density in the vicinity of the workplace. Spending per worker near employer premises is $\$ 150$ per week or less in the lower half of the population density distribution but nearly $\$ 300$ at the top end. The right panel shows that planned levels of WFH rise strongly with population density in the employer's vicinity. Thus, the projected shift to WFH is greater for employers in denser areas, and the loss in spending per worker is also greater. These figures reinforce the view that dense urban areas, in particular, will see less spending by inward commuters in the post-pandemic economy than they enjoyed before COVID.

To quantify this point, we project the implied worker spending drop and express it as a percentage of overall consumer spending in selected urban areas. Relative to the pre-pandemic situation, the shift to WFH in the post-pandemic economy reduces weekly spending near employer premises by $S P_{i}\left(W F H_{i}^{\text {Plan }}-W F H_{i}^{\text {Pre }}\right)$ for individual $i$, where $S P_{i}$ is average daily spending near his or her worksite in 2019 and the second term is the planned change in days per week WFH for person $i$. Among inward commuters to urban area $U$, the average drop in weekly worker spending near employer premises is

$$
A v g S p D r o p=\left(\sum_{i \ni I n U}^{U} S_{i}\right)^{-1} \sum_{i \ni I n U} S_{i} S P_{i}\left(W F H_{i}^{\text {Plan }}-W F H_{i}^{\text {Pre }}\right),
$$

where $s_{i}$ is a sample weight; and the average gain among outward commuters from $U$ is

$$
\operatorname{AvgSpGain}_{\text {Out }}^{U}=\left(\sum_{i \ni O u t U} S_{i}\right)^{-1} \sum_{i \ni O u t U} S_{i} S P_{i}\left(W F H_{i}^{\text {Plan }}-W F H_{i}^{\text {Pre }}\right) .
$$

Assuming 50 work weeks per year, we obtain the projected net drop in worker spending in area $U$ as a fraction of the area's overall consumer spending in 2019:

$$
\frac{\left.50\left[\operatorname{AvgSpDrop}_{I n}^{U} \text { (\# Inward Commuters for } U\right)-\operatorname{AvgSpGain} U \text { Out }(\# \text { Outward Commuters for } U)\right]}{\text { Overall Consumer Spending in Area } U \text { in } 2019}
$$

Multiplying this quantity by 100 yields our projection for the percentage reduction in consumer spending in urban area $U$ due to the greater extent of WFH in the post-pandemic economy (again, relative to the pre-pandemic situation). 
This draft implements a simpler calculation for two urban areas. Specifically, SWAA respondents who work in Manhattan (San Francisco) spent an average of \$288 (\$168) per week near their workplaces before COVID. The plans of Manhattan (San Francisco) employers imply that 35 (43) percent of post-COVID workdays will be supplied from home. Multiplying by the net daily number of inward commuters - 2.3 million for Manhattan and 200,000 for San Francisco yields annual spending drops of $\$ 12$ Billion for Manhattan and $\$ 0.8$ Billion for San Francisco. ${ }^{30}$ Scaling by 2019 taxable sales in each location, ${ }^{31}$ we project that greater WFH in the post-COVID economy will reduce consumer spending by 13\% in Manhattan and 4.6\% in San Francisco.

Our simplified calculations neglect the cross-sectional correlation between the COVIDinduced shift to WFH and spending near the workplace. Empirically, persons with plans for larger WFH increases spent more near their places of work before COVID. The fuller calculation described above will address this issue. Our current figures also understate the drops in and around major commercial districts, because our commuting numbers do not include persons who commute from, say, uptown Manhattan to the downtown financial district.

\section{d. The re-optimization of working arrangements will raise productivity}

How will a persistent shift to WFH affect productivity? In a field experiment, Bloom et al. (2015) find that call center workers are, on average, more productive when WFH. Whether their finding extends to the broader workforce is an open question. A priori, it's unclear whether offices or homes are more conducive to productivity on balance. Undoubtedly, it depends on circumstances, the organization, the nature of the job, the tasks to be performed, and the person. While we cannot implement a tight experimental design as in Bloom et al., we can project the broader productivity gains associated with more WFH in the post-COVID economy. We aim to quantify "true" productivity gains, inclusive of the savings in commuting time, and productivity gains as conventionally measured by statistical authorities. The conventional approach ignores time spent commuting, which misses much of the gain associated with a shift to WFH.

\footnotetext{
${ }^{30}$ The Manhattan commuting figure is from Moss and King (2012), and the one for San Francisco is from www.vitalsigns.mtc.ca.gov/commute-patterns.

31 In San Francisco, 2019 sales tax receipts were \$16.9 Billion (Source: https:/www.cdtfa.ca.gov/dataportal/dataset.htm?url=TaxSalesByCounty). In New York City they were \$182 Billion (Source: https://data.ny.gov/Government-Finance/Taxable-Sales-And-Purchases-QuarterlyData-Beginni/ny $73-2 j 3 \mathrm{u} /$ data.) Taxable sales are not separately reported for Manhattan, so we assume Manhattan accounts for half of all taxable sales, which seems reasonable given Manhattan attracts more businesses and tourists than the rest of the city but has a minority of the population.
} 
We start by estimating the productivity gain implied by the savings in commuting time. For an individual, the projected weekly time savings associated with greater WFH in the postpandemic economy is the reduction in commuting time, adjusted for the fraction of commute time devoted to work-related activities:

$$
T S_{i}=\left(W F H_{i}^{\text {Plan }}-W F H_{i}^{\text {Pre }}\right)\left(1-f_{i}\right) C_{i}
$$

where $C_{i}$ is the daily round-trip commute time when working on employer premises, expressed in hours, and $f_{i}$ is the fraction of commute time devoted to work-related activities. Thus, the implied productivity gain for individual $i$, expressed in percentage terms, is given by

$$
\operatorname{Gain}_{i}^{\text {Imp }}=100 \frac{T S_{i}}{L_{i}}=100 \frac{\left(W_{F H}^{\text {Plan }}-W F H_{i}^{\text {Pre }}\right)\left(1-f_{i}\right) C_{i}}{H_{i}^{\text {Pre }^{2}}+C_{i}\left(\text { Days }_{i}^{\text {Pre }}-W F H_{i}^{\text {Pre }}\right)},
$$

where $L_{i}$ denotes total weekly hours devoted to paid work, inclusive of commuting time, Days ${ }_{i}^{\text {Pre }}$ is the number of full workday per week before COVID, and $H_{i}^{\text {Pre }}$ is the conventional measure of weekly work hours based on responses to the following question: "In 2019 (before COVID) approximately how many hours a week did you work when employed?". Implementing these calculations in the SWAA micro data, the average implied productivity gain due to less commuting is $1.9(0.1)$ percent on an equal-weighted basis and $2.5(0.1)$ percent an on earnings-weighted basis. ${ }^{32}$ The large size of these implied gains underscores how a persistent increase in WFH will bring a large, continuing flow of aggregate benefits in the form of reduced commuting time.

We now estimate the total (true) productivity gain associated with greater WFH in the postpandemic economy - again, as compared to the pre-pandemic situation. To assess relative productivity when WFH, we draw on responses to a series of questions in the SWAA. The first one goes to all persons who report WFH at some point during the pandemic: ${ }^{33}$

How does your efficiency working from home during the COVID-19 pandemic compare to your efficiency working on business premises before the pandemic?

- Better -- I am more efficient at home than I was working on business premises

- About the same -- I'm equally efficient in both places

\footnotetext{
32 The larger gain on an earnings-weighted basis is no surprise, given the strong positive relationship of earnings to $W F H_{i}^{\text {Plan }}$ (Figure 8) and to commute time (Figure A.2).

${ }^{33}$ As with the question about the perk value of working from home, earlier versions of this question did not use a two-part approach or used a different level of disaggregation for the choices. For Figure 10, we focus on survey waves where the questions and choices are comparable.
} 
- Worse -- I am less efficient at home than I was working on business premises

For those who respond "Better" ["Worse"], we follow up with:

How much more [less] efficient have you been working from home during the COVID-19 pandemic than on business premises before the COVID-19 pandemic?

Response options are: Under 5\% more [less] efficient; 5 to 10\% more [less] efficient; 10 to 15\% more [less] efficient; 15 to 25\% more [less] efficient; 25 to 35\% more [less] efficient; and Over $35 \%$ more [less] efficient. Figure 10 shows the response distribution. Forty-five percent of workers say they were about as efficient WFH during the pandemic as working on business premises before the pandemic. However, 40 percent say they are more efficient when WFH, and one-fifth say they are at least 15 percent more efficient. These results suggest that the pandemic-induced shift to WFH will raise productivity. In addition, the extent of mainly WFH during COVID, desires for WFH after COVID, and employer plans for WFH after COVID all correlate positively with selfassessed relative efficiency when WFH (Figure A.4).

To develop an estimate for the overall true productivity gain, we proceed as follows. First, we assign midpoint values to the response bins and calculate each person's self-assessed WFH productivity gain, $\operatorname{PrDiff} f_{i}$. To help interpret this quantity, we also ask persons with $\operatorname{PrDiff} f_{i}>0$ whether a part of their self-assessed productivity advantage when WFH reflects reduced commuting time. They say "yes" about 85 percent of the time, and when they do we follow up by asking how much of the WFH productivity advantage is due to reduced commuting time. Second, we calculate the individual-level true productivity gain, in percentage terms, as

$$
\operatorname{Gain}_{i}^{\text {True }}=\operatorname{PrDiff}_{i}\left(\frac{W F H_{i}^{\text {Plan }}-W F H_{i}^{\text {Pre }}}{\operatorname{Days}_{i}}\right)+\mathcal{X}_{i} \operatorname{Gain}_{i}^{\text {Imp }}
$$

where $\mathcal{X}_{i}$ is an indicator variable equal to 1 when the respondent's WFH productivity advantage excludes the role of commuting time savings. ${ }^{34}$

Using equation (6), we estimate that the COVID-induced shift to WFH will boost true productivity in the post-pandemic economy by $3.6(0.2)$ percent on an equal-weighted basis and by $4.6(0.2)$ percent on an earnings-weighted basis. These gains are quite large, providing more support for the view that the COVID-induced shift to WFH will yield important benefits in the form of more output per unit of time devoted to working for pay, inclusive of commuting time.

\footnotetext{
${ }^{34}$ In implementing (4), we set $\operatorname{Gain}_{i}^{\text {True }}$ to zero when $\operatorname{PrDiff}_{i}<0$, on the view that people who are less productive when WFH won't. In practice, this assumption has a negligible impact on the results.
} 
Finally, we calculate the conventionally measured productivity gain for an individual as

$$
\operatorname{Gain}_{i}^{\text {Conv }}=\left(1-\delta_{i}\right) \operatorname{PrDiff}_{i}\left(\frac{W F H_{i}^{\text {Plan }}-W F H_{i}^{\text {Pre }}}{\text { Days }_{i}}\right),
$$

where $\delta_{i}$ is the fraction of the self-assessed efficiency advantage of WFH that the respondent attributes to reduced commuting time. Using (7) we estimate that the COVID-induced shift to WFH will boost conventionally measured productivity in the post-pandemic economy by $0.8(0.1)$ percent on an equal-weighted basis and $1.0(0.1)$ percent on an earnings-weighted basis. ${ }^{35}$ These gains are only a fraction of our estimates for the true productivity gains.

Our estimates for the efficiency impact of the COVID-induced shift to WFH are surely imperfect. For example, our productivity gain figures might be underestimates, because we ask about WFH productivity during COVID, which involves negative effects of pandemic-related stress and kids at home due school closures. Alternatively, our productivity gain figures could be overestimates if workers fail to internalize the benefits of in-person interactions that contribute to firm-level productivity. Other potential sources of bias involve survey response errors and an imperfectly representative sample. On balance, however, our results suggest that higher WFH levels in the post-pandemic economy will boost true productivity by nearly five percent, while the boost in conventionally measured productivity will be much smaller.

\section{Concluding Remarks}

Much of the COVID-induced shift to WFH will stick long after the pandemic ends. Using data from the ongoing Survey of Working Arrangements and Attitudes, we project that American workers will supply about 20 percent of full workdays from home in the post-pandemic economy, four times the pre-COVID level. Desires to work from home part of the week are pervasive across groups defined by age, education, gender, earnings, and family circumstances. Indeed, most workers express a willingness to accept sizable pay cuts in return for the option to work from home two or three days a week. In this respect, a large shift to WFH is a welcome development.

Employer plans imply that the extent of WFH will rise sharply with education and earnings in the post-pandemic economy. These plans align well with worker desires at the upper end of the earnings distribution, but not for others. For most workers, the post-pandemic economy will entail

\footnotetext{
${ }^{35}$ In practice, the effect of a shift to WFH on conventional productivity measures also depends on measurement errors in reported labor inputs. Suppose, for example, that employees report 40 workhours per week regardless of actual workhours. In this case, if actual workhours rise due to a shift to WFH, the conventional measure of hourly productivity would also rise.
} 
more WFH than in the pre-COVID economy but considerably less than they would like. To put it another way, the benefits of a persistent shift to WFH will be broadly felt but flow mainly to the better educated and the highly paid.

We also explain why the COVID-induced shift to WFH will, in large measure, stick long after the pandemic ends. Perhaps most important, forced experimentation with WFH during the pandemic revealed information that alters future plans for the extent of WFH after the pandemic ends, in line with the prediction of our theoretical framework. The gist of our evidence on forced experimentation and learning is nicely encapsulated in a remark by James Gorman, CEO of Morgan Stanley: "If you'd said three months ago that $90 \%$ of our employees will be working from home and the firm would be functioning fine, I'd say that is a test I'm not prepared to take because the downside of being wrong on that is massive" (Cutter 2020). Other mechanisms that contribute to stickiness in the shift to WFH include pandemic-induced investments to enable WFH, greatly diminished stigma associated with WFH, long lingering fears about mingling and proximity to others, and a pandemic-driven surge in innovations that support WFH.

Higher levels of WFH will present pointed challenges for urban areas, especially cities with high rates of inward commuting by well-paid professionals in the pre-COVID environment. As these workers cut back on commuting, they will spend less on food, shopping, personal services, and entertainment near workplaces clustered in city centers. In preliminary calculations that exploit our survey data, we project that overall consumer spending will drop 5 to 10 percent or more (relative to the pre-pandemic situation) in San Francisco and Manhattan because of declines in net inward commuting and less spending near employer premises. Their central business districts will see considerably larger spending drops relative to the pre-pandemic levels.

We also estimate that higher levels of WFH will boost productivity by about 4.6 percent. Over half of this productivity gain reflects the savings in commuting time afforded by WFH. These true productivity gains will go largely unrecorded in conventional productivity statistics, because they do not encompass the effects of reduced commuting time. Indeed, when we mimic the conventional approach, we estimate a comparatively paltry 1.0 percent productivity boost from higher WFH levels in the post-pandemic economy. 


\section{References}

Acemoglu, Daron, 2002. "Directed technical change," Review of Economic Studies, 69, 781-809. Acemoglu, Daron and Joshua Lin, 2004. "Market Size in Innovation: Theory and Evidence from the Pharmaceutical Industry," Quarterly Journal of Economics, 119, no. 3, 1049-1090.

Adams-Prassl, Abi, Teodora Boneva, Marta Golin, and Christopher Rauh. 2020 "Inequality in the Impact of the Coronavirus Shock: Evidence from Real Time Surveys." CEPR Discussion Paper 14665.

Alon, Titan, Matthias Doepke, Matthias, Jane Olmstead-Rumsey and Michele Tertilt, 2020a. "The Impact of COVID-19 on Gender Equality," NBER Working Paper 26947.

Alon, Titan, Doepke, Matthias, Jane Olmstead-Rumsey and Michele Tertilt, 2020b. "This time it's different: The Role of Women's Employment in a Pandemic Recession," NBER Working Paper 27660.

Althoff, Lukas, Fabian Eckert, Sharat Ganapati and Conor Walsh, 2020. "The City Paradox: Skilled Services and Remote Work," CESifo working paper no. 8734.

Altig, David, Jose Maria Barrero, Nick Bloom, Steven J. Davis, Brent Meyer, Emil Mihaylov and Nick Parker, 2020a. "Firms Expect Working from Home to Triple," Macroblog, 28 May.

Altig, David, Jose Maria Barrero, Nick Bloom, Steven J. Davis, Brent Meyer, Emil Mihaylov and Nick Parker, 2021. "WFH Is Onstage and Here to Stay," Macroblog, 25 February.

Altig, David, Jose Maria Barrero, Nick Bloom, Steven J. Davis, Brent Meyer and Nick Parker, 2020b. "Surveying Business Uncertainty." Forthcoming, Journal of Econometrics.

Angelici, Marta and Paola Profeta, 2020, "Smart working: Flexibility without constraints," CES working paper no. 8165 .

Bajowaa, Sakina S., Jacob Milosch and Chandani Bansal, 2020. "Telemedicine Pays: Billing and Coding Update," Current Allergy and Asthma Reports, 20, no. 60.

Barrero, Jose Maria, Nicholas Bloom, and Steven J. Davis, 2020a. "60 Million Fewer Commuting Hours per Day: How Americans Use Time Saved by Working from Home," VoxEU CEPR Policy Portal, 23 September.

Barrero, Jose Maria, Nicholas Bloom, and Steven J. Davis, 2020b. "COVID-19 Is Also a Reallocation Shock," Brookings Papers on Economic Activity, Summer, 329-371.

Barrero, Jose Maria, Nicholas Bloom, and Steven J. Davis, 2021. "Question Repository for the Survey of Working Arrangements and Attitudes," available at www.WFHresearch.com.

Barrero, Jose Maria, Nicholas Bloom, Steven J. Davis, and Brent H. Meyer, 2021. "COVID-19 Is a Persistent Reallocation Shock," AEA Papers and Proceedings, May.

Bartik, Alexander W., Zoe B. Cullen, Edward L. Glaeser, Michael Luca, and Christopher T. Stanton, 2020. "What Jobs are Being Done at Home During the Covid-19 Crisis?

Evidence from Firm-Level Surveys," NBER Working Paper No. 27422.

Behrens, Kristian, Sergey Kichko, Jackques-Francois Thisse, 2021. "Working from Home: Too Much of a Good Thing?" CESifo Working Paper No. 8831.

Bick, Alexander and Adam Blandin, 2021. "Real-Time Labor Market Estimates During the 2020 Coronavirus Outbreak," working paper, 22 January.

Bick, Alexander, Adam Blandin, and Karel Mertens, 2020. "Work from Home After the COVID19 Outbreak," Federal Reserve Bank of Dallas Working Paper. 
Bloom, Nicholas, Steven J. Davis, and Yulia Zhestkova, 2021. "COVID-19 Shifted Patent Applications toward Technologies that Support Working from Home." American Economic Association, Papers \& Proceedings, May.

Bloom, Nicholas, James Liang, John Roberts, and Zhichun Jenny Ying, 2015. "Does working from home work? Evidence from a Chinese experiment," Quarterly Journal of Economics, 130, no. $1,165-218$.

Bloom, Nicholas, Tobias Kretschmer and John Van Reenen, "Work-life Balance, Management Practices and Productivity', in International Differences in the Business Practice and Productivity of Firms, Richard Freeman and Kathryn Shaw, eds. (Chicago, IL: University of Chicago Press, 2009).

Brynjolfsson, Erik, John J. Horton, Adam Ozimek, Daniel Rock, Garima Sharma, and Hong-Yi TuYe, 2020. "COVID-19 and Remote Work: An Early Look at US Data," NBER Working Paper No. 27344.

Bureau of Labor Studies (2018), "Job Flexibilities and Work Schedules - 2017-2018 Data from the American Time Use Survey," https://www.bls.gov/news.release/flex2.nr0.htm

Bunk, Scott, Clark, David and James McGibany, 2006, "Evaluating the long-run impacts of the 9/11 terrorist attacks on US domestic airline travel," Applied Economics, 38, 363-370.

Choudhury, Prithwiraj, Cirrus Foroughi, and Barbara Zepp Larson, 2021. "Work-from-anywhere: The productivity effects of geographic flexibility," Strategic Management Journal, 42, no. 4, 655-683.

Cicala, Steve, 2020. "Powering work from home,” NBER Working Paper No. 27937.

Coibion, Olivier, Gorodnichenko, Yuriy and Michael Weber, 2020. "The cost of the COVID-19 crisis: Lockdowns, macroeconomic expectations, and consumer spending," BFI Working Paper 2020-60.

Cooper, Russell and Andrew John, 1988. "Coordinating Coordination Failures in Keynesian Models," Quarterly Journal of Economics, 103, no. 3 (August), 441-463.

Davis, Steven J., Stephen Hansen, and Cristhian Seminario-Amez, 2021. "Firm-Level Risk Exposures and Stock Returns in the Wake of COVID-19," NBER Working Paper 27867.

Del Boca, Daniela, Noemi Oggero, Paola Profeta and Maria Christina Rossi, 2020. "Women's Work, Housework, and Childcare, Before and During COVID-19," CESifo w.p. 8403.

DeFilippis, Evan, Stephen Michael Impink, Madison Singell, Jeffrey Polzer, and Raffaella Sadun, 2020, "Collaborating during coronavirus: The impact of COVID-19 on the nature of work," NBER Working Paper No. 27612.

De Fraja, Gianni, Jesse Matheson and James Rockey, 2021. "Zoomshock: The geography and local labour market consequences of working from home," Covid Economics 64, 1-41.

Deole, Sumit, Max Deter and Yeu Huang, 2021. "Home Sweet Home: Working from Home and Employee Performance during the COVID-19 Pandemic in the U.K.," working paper.

Eberly, Janice, 2020. "Comments on Barrero and Bloom," remarks at the Jackson Hole Economic Symposium.

Emanuel, Natalia and Emma Harrington, 2021, "Working' remotely? Selection, treatment and the market provision of remote work," working paper, 9 April.

Favilukis, Jack, Xiaoji Lin, Ali Sharifkhan and Xiaofei Zhao, 2020. "Labor Force Telework Flexibility and Asset Prices: Evidence from the COVID-19 Pandemic," working paper.

Gupta, Arpit, Vrinda Mittal, Jonas Peeters and Stijn Van Nieuwerburgh, 2021. "Flattening the Curve: Pandemic-Induced Revaluation of Urban Real Estate," COVID Economics, 69. 
Hopkins, Jared S., 2020. "Ahead of Covid-19 Vaccine, Half of Americans Indicate Reluctance, WSJ/NBC Poll Finds.” Wall Street Journal, October 15.

Jerbashian, Vahagn and Montserrat Vilalta-Buffi, 2020. "The Impact of ICT on Working from Home: Evidence from EU Countries," GLO Discussion Paper No. 719.

Kahn, Lisa B., Fabian Lange, and David G. Wiczer. 2020. "Labor Demand in the Time of COVID19: Evidence from Vacancy Postings and UI Claims.” NBER Working Paper 27061.

Kremer, Michael, 2002. "Pharmaceuticals and the Developing World," Journal of Economic Perspectives, 16, no. 4 (Fall), 67-90.

Kunn, Steffen, Christian Seel and Dainis Zegners, 2020, "Cognitive performance in the home office - evidence from professional chess," IZA Discussion Paper No. 13491.

Larcom, Shaun, Ferdinand Rauch, and Tim Willems, 2017. "The Benefits of Forced Experimentation: Striking Evidence from the London Underground Network," Quarterly Journal of Economics, 132, no. 4, 2019-2055.

Liu, Sitian and Yichen Su, 2020. "The Impact of the COVID-19 Pandemic on the Demand for Density: Evidence from the US Housing Market," working paper, Queens University.

Mas, Alexandre and Amanda Pallais, "Valuing alternative work arrangements," American Economic Review, 2017, 107, no. 12, 3722-59

Mas, Alexander and Amanda Pallais, "Alternative Work Arrangements," Annual Review of Economics, 12, 631-658.

Mateyka, Petr J., Melanie Rapino and Liana Christin Landivar, 2012. "Home-Based Workers in the United States: 2010," United States Census Bureau, Current Population Reports.

Mims, Christopher, 2020. "The Next Phase of the Retail Apocalypse: Stores Reborn as ECommerce Warehouses," Wall Street Journal, 18 July.

Möhring, Katja, Elias Naumann, Maximiliane Reifenscheid, Alexander Wenz, Tobias Rettig, Ulrich Krieger, Sabine Friedel, Marina Finkel, Carina Cornesse and Annelies G. Blom, 2021. "The COVID-19 pandemic and subjective well-being: longitudinal evidence on satisfaction with work and family," European Societies, 23.

Mongey, Simon, Laura Pilossoph, and Alex Weinberg. 2020. "Which Workers Bear the Burden of Social Distancing Policies?" NBER Working Paper 27085.

Moss, Mitchell L. and Carson King, 2012. "The Dynamic Population of Manhattan." NYU Wagner School of Public Service Working Paper.

Naughton, Nora, 2020. "The Pandemic Has Pushed Car Buying Online. It's Expected to Stick," Wall Street Journal, 20 June.

Ozimek, Adam, 2020. "The future of remote work," SSRN Working Paper.

Pabilonia, Sabrina and Victoria Vernon, 2021. "Telework, wages, and time use in the United States," GLO Discussion Paper No. 546.

Pagano, Marco, Christian Wagner and Josef Zechner, 2020. "Disaster Resilience and Asset Prices," working paper.

Papanikolaou, Dimitris, and Lawrence D. W. Schmidt. 2020. "Working Remotely and the Supplyside Impact of Covid-19.” NBER Working Paper 27330.

Putzier, Konrad, 2021. "Hotel Owners Continue to Reel from the Pandemic," Wall Street Journal, 2 January.

Ramani, Arjun and Nick Bloom, 2021. "The Donut Effect: How COVID-19 Shapes Real Estate," SIEPR Policy Brief, January.

Rothschild, Michael, 1974. "Searching for the Lowest Price When the True Distribution of Prices Is Unknown," Journal of Political Economy, 82, no. 4, 689-711. 
Schmookler, Jacob, 1966. Innovation and Economic Growth. MIT Press.

Prescott, J.J., Norman Bishara, and Evan Starr, 2016. "Understanding noncompetition agreements: the 2014 noncompete survey project." Michigan State Law Review, 369-464.

Stanton, Christopher T. and Pratyush Tiwari, 2021. "Housing Consumption and the Cost of Remote Work," NBER Working Paper 28483.

Starr, Evan, J.J. Prescott and Norman Bishara, 2020. "Noncompete Agreements in the U.S. Labor Force," Journal of Law and Economics, forthcoming.

Steemers, Frank, Robin Erickson, Amanda Popiela and Gad Levanon, 2020. "Adapting to the Reimagined Workplace: Human Capital Responses to the COVID-19 Pandemic," Conference Board, October.

Taneja. Shivani, Paul Mizen and Nicholas Bloom, 2021. "Working from home is revolutionising the UK Labour market," VoxEU CEPR Policy Portal, 15 March.

Torry, Harriet, 2020. “Pandemic Speeds Americans' Embrace of Digital Commerce," Wall Street Journal, 15 November.

Tyson, Alec, Courtney Johnson, and Cary Funk, 2020. "U.S. public now divided over whether to get COVID-19 vaccine," Pew Research Center report.

Webster, Paul, 2020. "Virtual Health Care in the Era of COVID-19," The Lancet, 395, issue 10231.

White, Dustin R., 2019. "Agency Theory and Work from Home," Labour, 33, no. 1, 1-25. 


\section{Figure 1: Extent of working from home before, during, and after COVID}

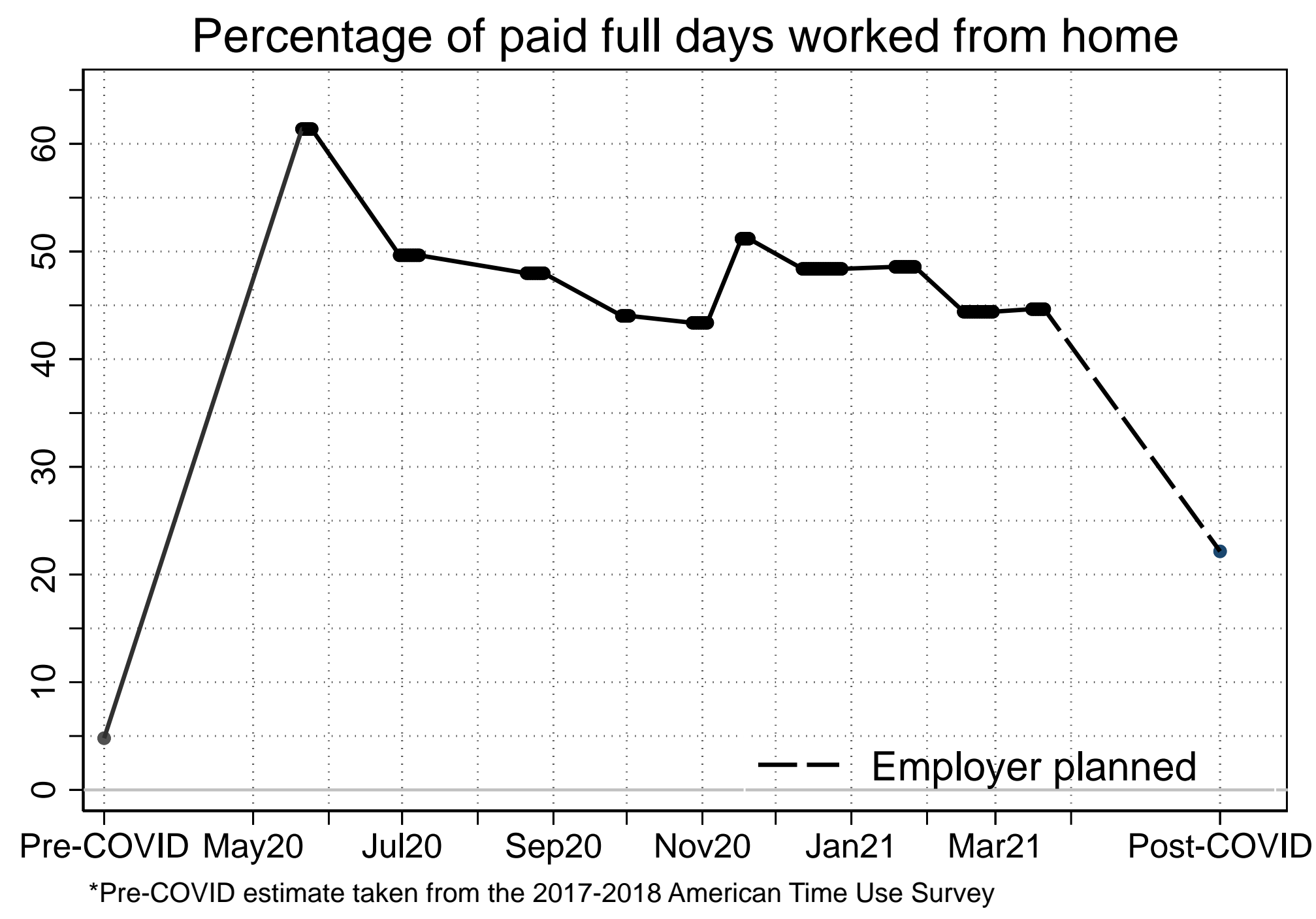

Source: Responses to the questions: "Currently (this week) what is your work status?" and "After COVID, in 2022 and later, how often is your employer planning for you to work full days at home?"

Notes: Data are from 33,250 survey responses collected between May 2020 and March 2021 by Inc-Query and QuestionPro. For each survey wave, we compute the average percentage of paid full days worked from home and plot it on the vertical axis against the days during which that wave was in the field on the horizontal axis. The pre-COVID estimate comes from the 2017-2018 American Time Use Survey (see Appendix A for details) and the post-COVID estimate uses data from the March 2021 wave. We re-weight the sample to match Current Population Survey data from 2010 to 2019 by age-sex-education-earnings cell. 
Figure 2: Survey responses compared to the CPS
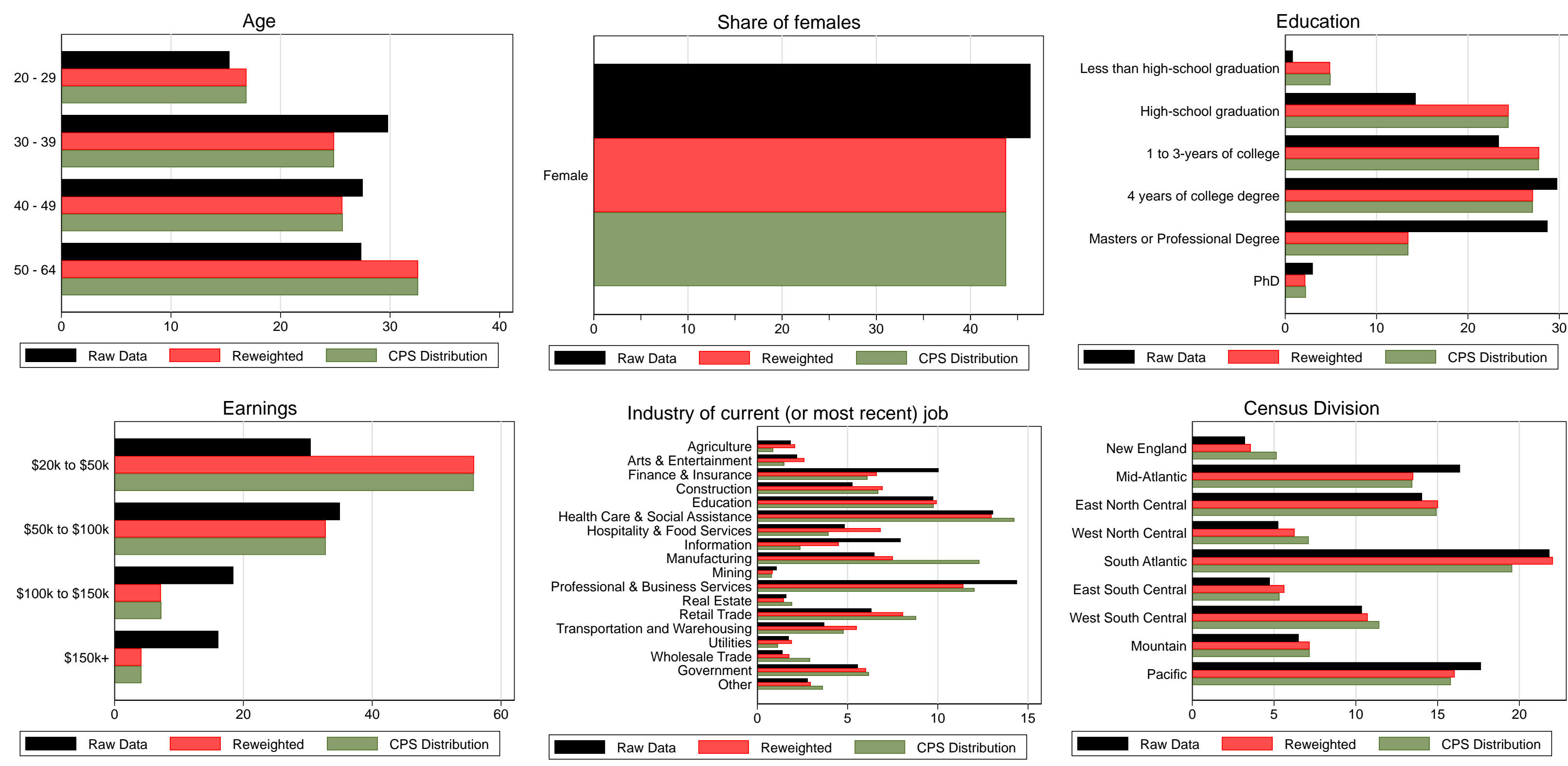

Notes: Each figure shows the distribution of raw survey responses, survey responses reweighted to match the share of persons aged 20 to 64 in a given age $x$ sex $x$ education $x$ earnings $\}$ cell in the $2010-2019$ CPS (focusing on those who earned more than $\$ 20,000$ a year), and the corresponding distribution in the CPS. Data are 37 from 33,250 survey responses collected between May 2020 and March 2021 by Inc-Query and QuestionPro. 


\section{Figure 3: Most workers want to work from home two or more days per week}

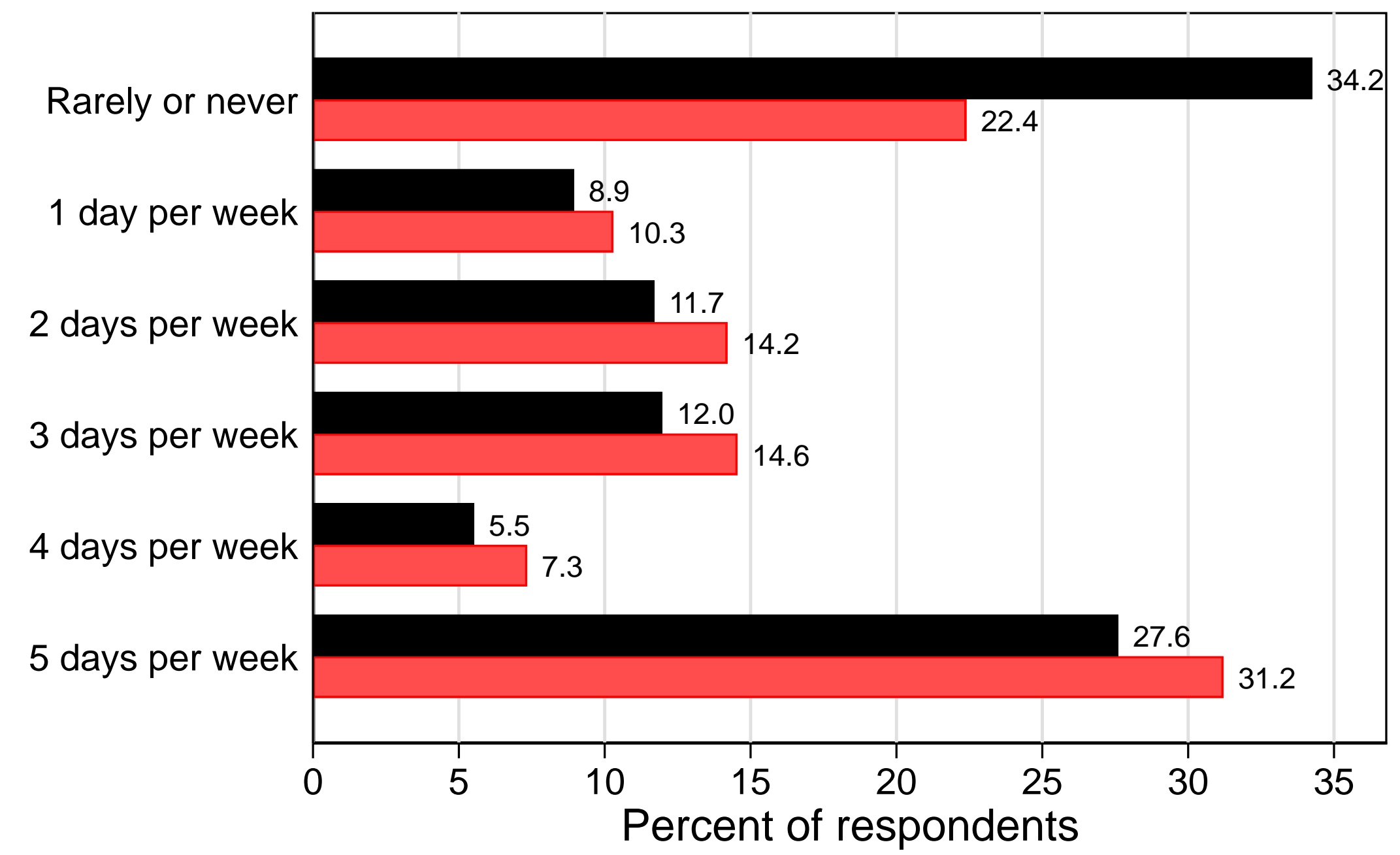

Source: Responses to the question:

In 2022+ (after COVID) how often would you like to have paid work days at home?

Notes: Data are from 33,250 survey responses collected from May 2020 through March 2021 by Inc-Query and QuestionPro. "Respondents able to WFH" are those who say they can work from home at least partially and those who report having mainly worked from home at some point during the COVID-19 pandemic. We re-weight raw responses to match the share of workingage respondents in the 2010-2019 CPS in a given age $x$ sex $x$ education $x$ earnings cell.
All respondents
Respondents able to WFH*

\begin{tabular}{|lll|}
\hline All respondents $\square$ Respondents able to $\mathrm{WFH}^{*}$ \\
\hline
\end{tabular}

${ }^{*} 64 \%$ of the full sample meets this criterion 


\section{Value of the option to WFH 2 - 3 days/wk, \% of current pay?}

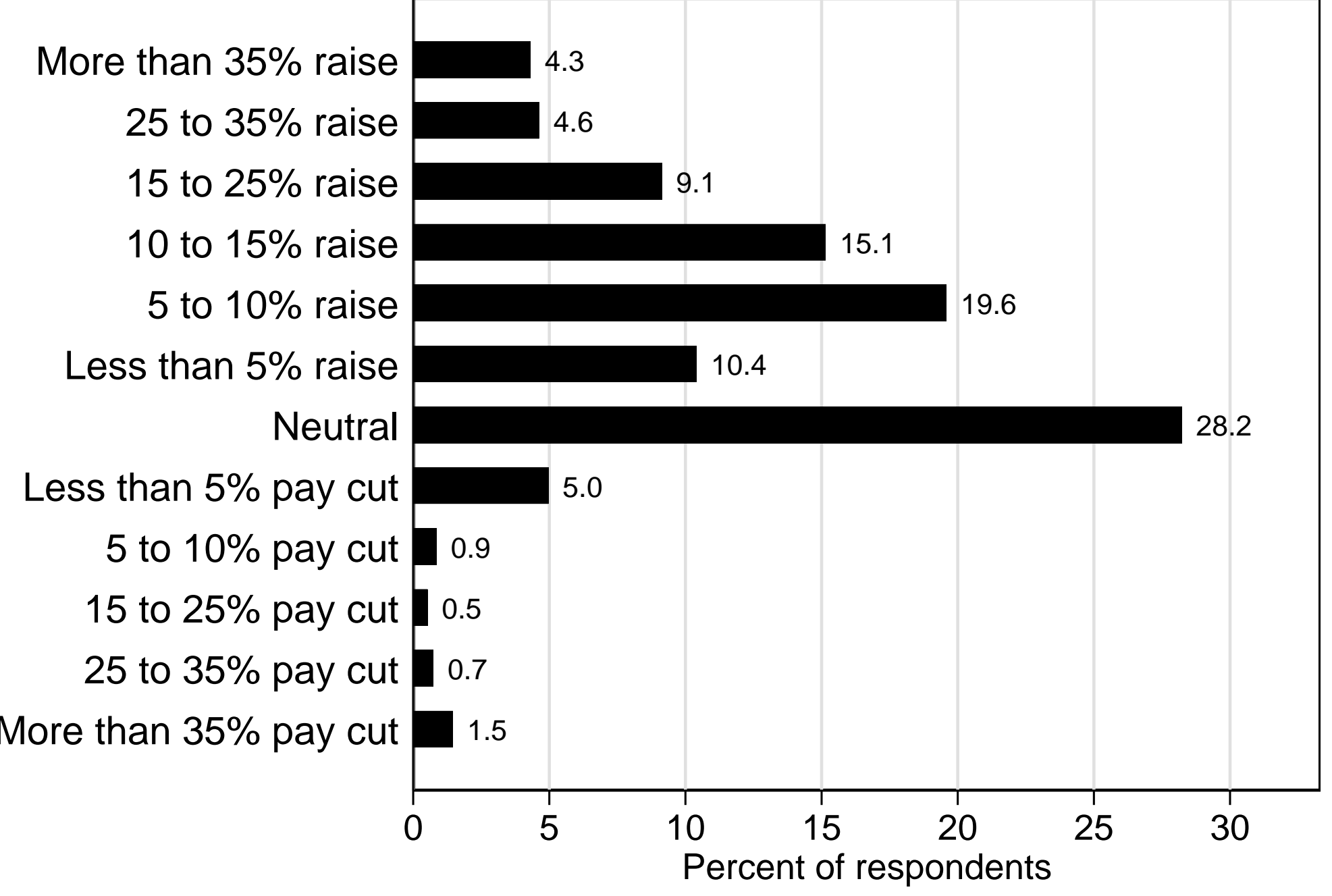

Source: Responses to a two-part question.

Part 1: After COVID, in 2022 and later, how would you feel about working from home 2 or 3 days a week?"

- Positive: I would view it as a benefit or extra pay

- Neutral

- Negative: I would view it as a cost or a pay cut

Part 2: How much of a pay raise [cut] (as a percent of your current pay) would you value as much as the option to work from home 2 or 3 days a week?

Data are from 20,750 survey responses collected from September 2020 to February 2021 by IncQuery and QuestionPro. We asked a similar question in earlier and subsequent waves, but we focus on the above waves, which use identical questions and response options. We re-weight raw responses to match the share of working age respondents in the 2010-2019 CPS in a given fage $x$ sex $x$ education $x$ earnings $\}$ cell. 


\section{Figure 5: Productivity when working from home has exceeded expectations}

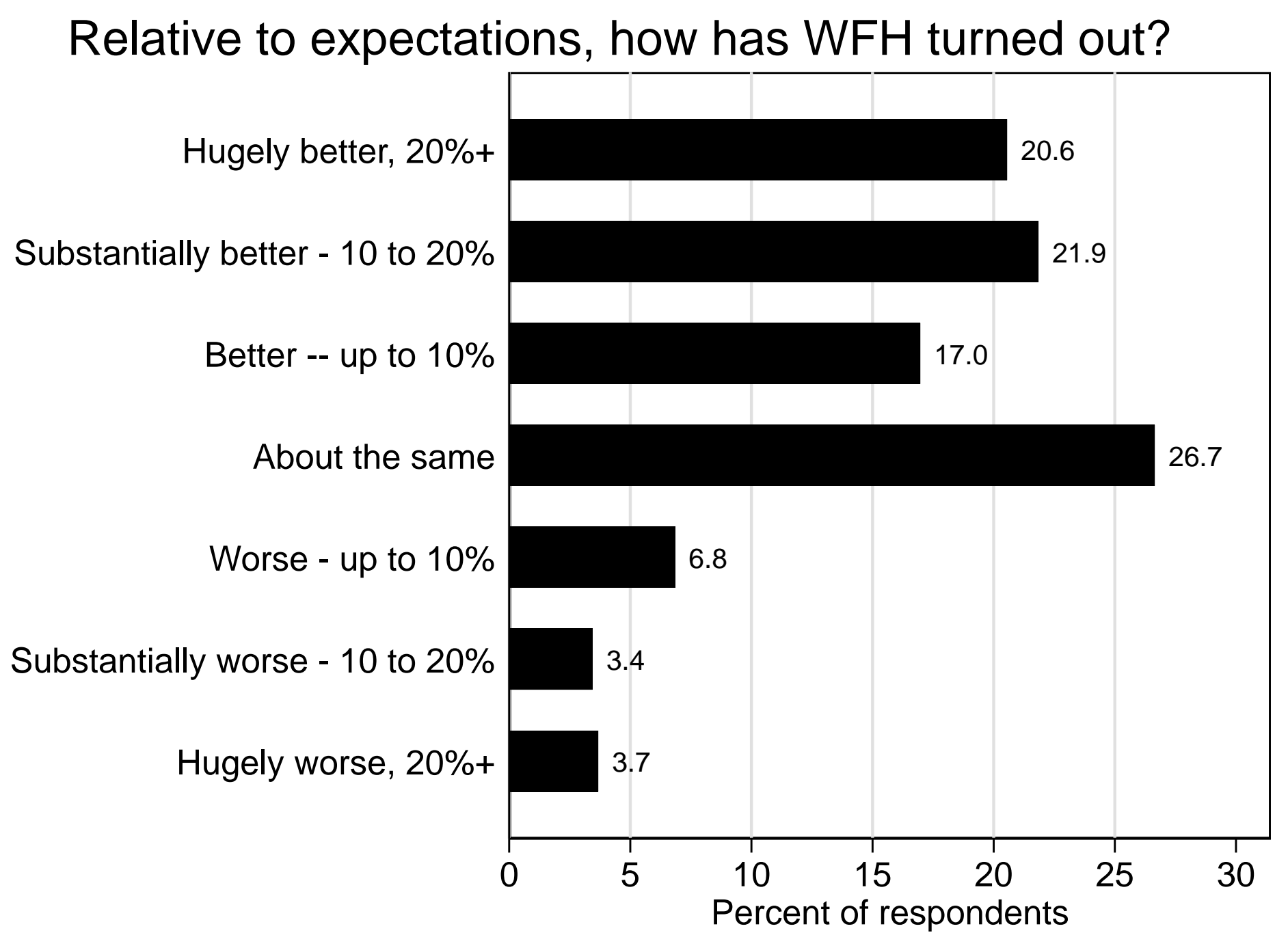

Source: Responses to the question:

Compared to your expectations before COVID (in 2019) how has working from home turned out for you?

- Hugely better -- I am 20\%+ more productive than I expected

- Substantially better -- I am to $10 \%$ to $19 \%$ more productive than I expected

- Better -- I am 1\% to 9\% more productive than I expected

- About the same

- Worse -- I am $1 \%$ to $9 \%$ less productive than I expected

- Substantially worse -- I am to $10 \%$ to $19 \%$ less productive than I expected

- Hugely worse -- I am $20 \%+$ less productive than I expected

Notes: Data are from 30,750 survey responses collected from July 2020 to March 2021 by Inc-Query and QuestionPro. We re-weight raw responses to match the share of working age respondents in the 2010-2019 CPS in a given fage $x$ sex $x$ education $x$ earnings $\}$ cell. We did not ask about productivity relative to expectations in May 2020. 


\section{Figure 6: Desired and planned levels of WFH after the pandemic increase with WFH productivity surprises during the pandemic}

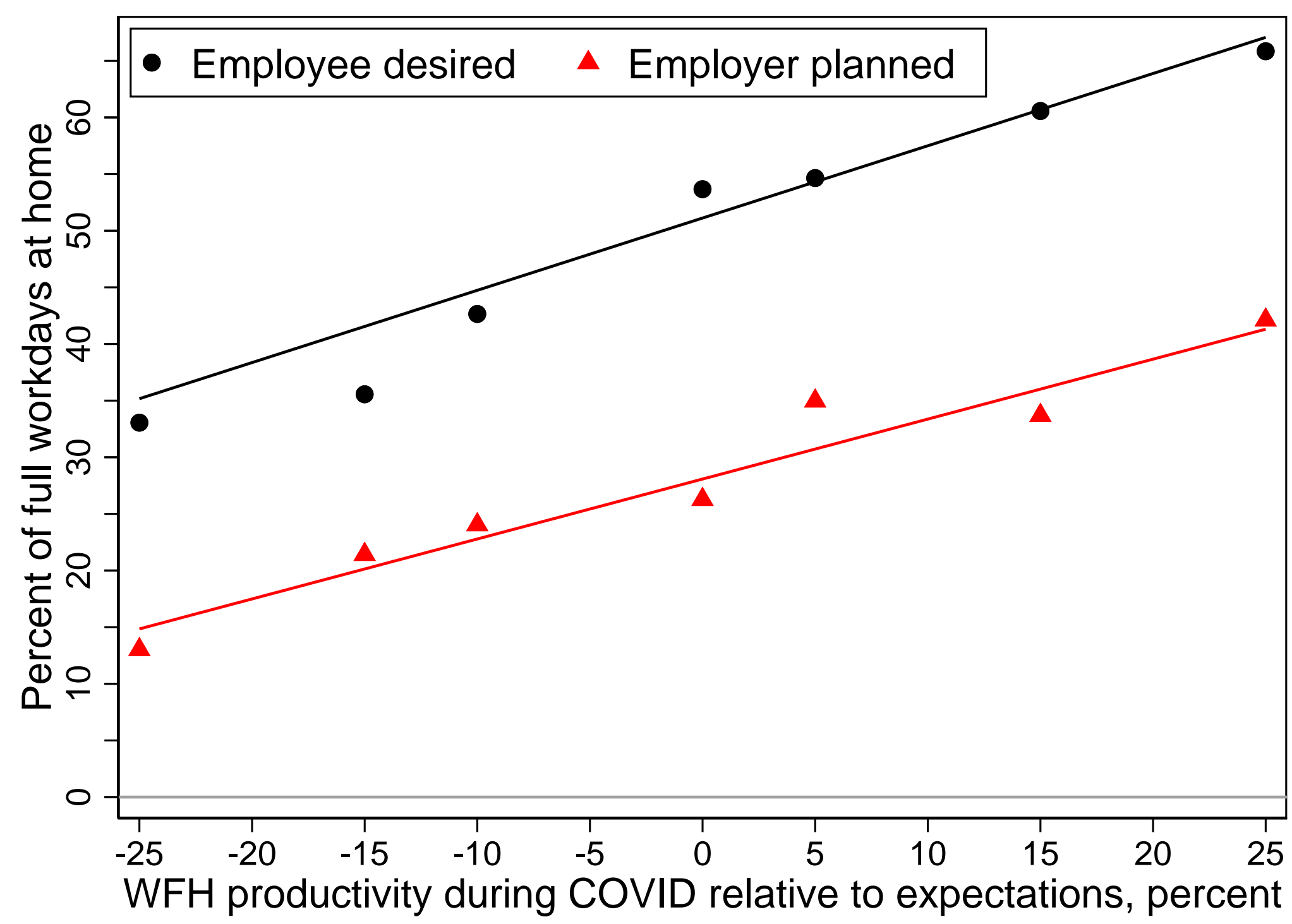

Source: Response to the questions:

After COVID, in 2022 and later, how often would you like to have paid workdays at home?

After COVID, in 2022 and later, how often is your employer planning for you to work full days at home?

Compared to your expectations before COVID (in 2019) how has working from home turned out for you?

Notes: This figure shows bin scatters of worker desires and employer plans for WFH after the pandemic against WFH productivity surprises during the pandemic.

Data are from 30,750 survey responses collected from July 2020 to March 2021 and reweighted to match the share of working age respondents in the 2010-2019 CPS in a given age $x$ sex $x$ education $x$ earnings $\}$ cell. We did not ask about productivity relative to expectations in May 2020. 


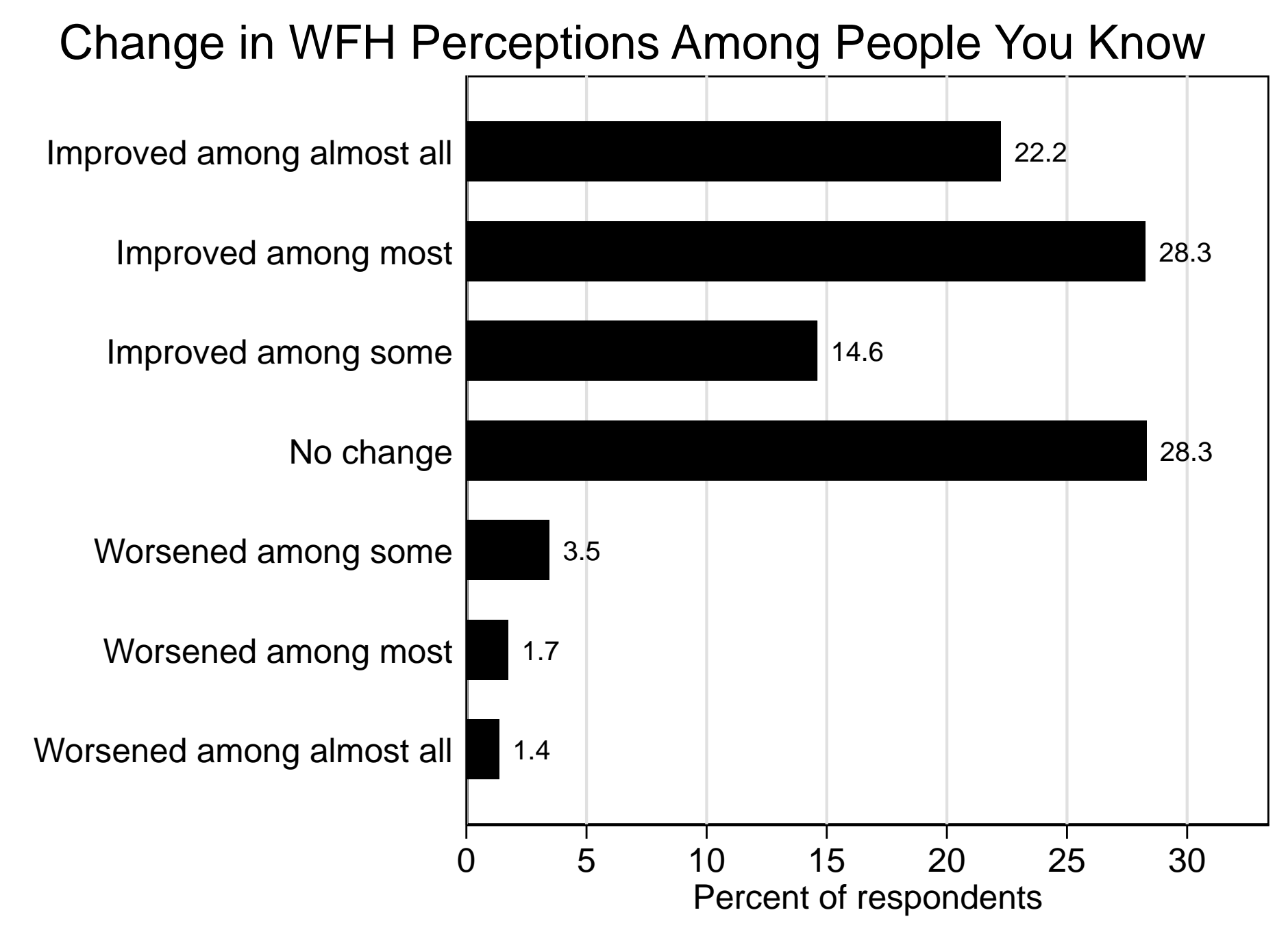

Source: Responses to the question:

Since the COVID pandemic began, how have perceptions about working from home (WFH) changed among people you know?

- Hugely improved -- the perception of WFH has improved among almost all (90-100\%) the people I know

- Substantially improved -- the perception of WFH has improved among most but not all of the people I know

- Slightly improved -- the perception of WFH has improved among some people I know but not most

- No change

- $\quad$ Slightly worsened -- the perception of WFH has worsened among some, but not most, people I know

- Substantially worsened -- the perception of WFH has worsened among most, but not all, people I know

- Hugely worsened -- the perception of WFH has worsened among almost all (90-100\%) the people I know

Notes: Data are from 30,750 survey responses collected between July 2020 and March 2021 by Inc-Query and QuestionPro. We re-weight raw responses to match the share of working age respondents in the 2010-2019 CPS in a given \{age $x$ sex $x$ education $x$ earnings \} cell. We did not ask about WFH perceptions in May 2020. 


\section{Figure 8: Worker desires for WFH increase modestly with earnings, but employer plans for WFH increase steeply with earnings.}

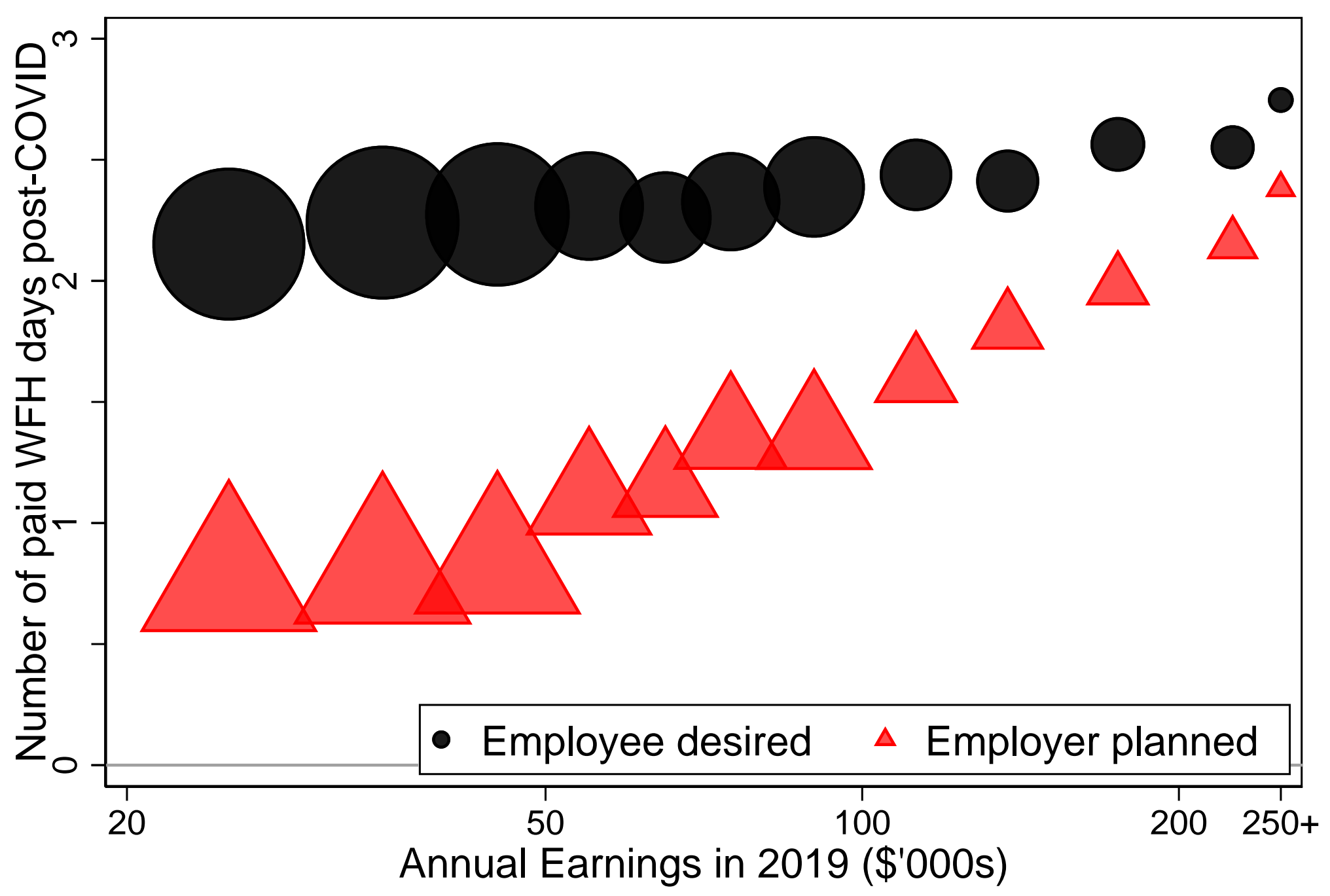

Note: Marker size is proportional to the number of respondents per income level.
Source: Response to the questions:

After COVID, in 2022 and later, how often would you like to have paid workdays at home?

After COVID, in 2022 and later, how often is your employer planning for you to work full days at home?

Notes: Data are from 30,750 survey responses collected between July 2020 and March 2021 by Inc-Query and QuestionPro. We re-weight raw responses to match the share of working age respondents in the 2010-2019 CPS in a given age $x$ sex $x$ education $x$ earnings $\}$ cell. We did not ask about employer plans in May 2020. 


\section{Figure 9: Spatial reallocation of worker spending away from dense city centers}

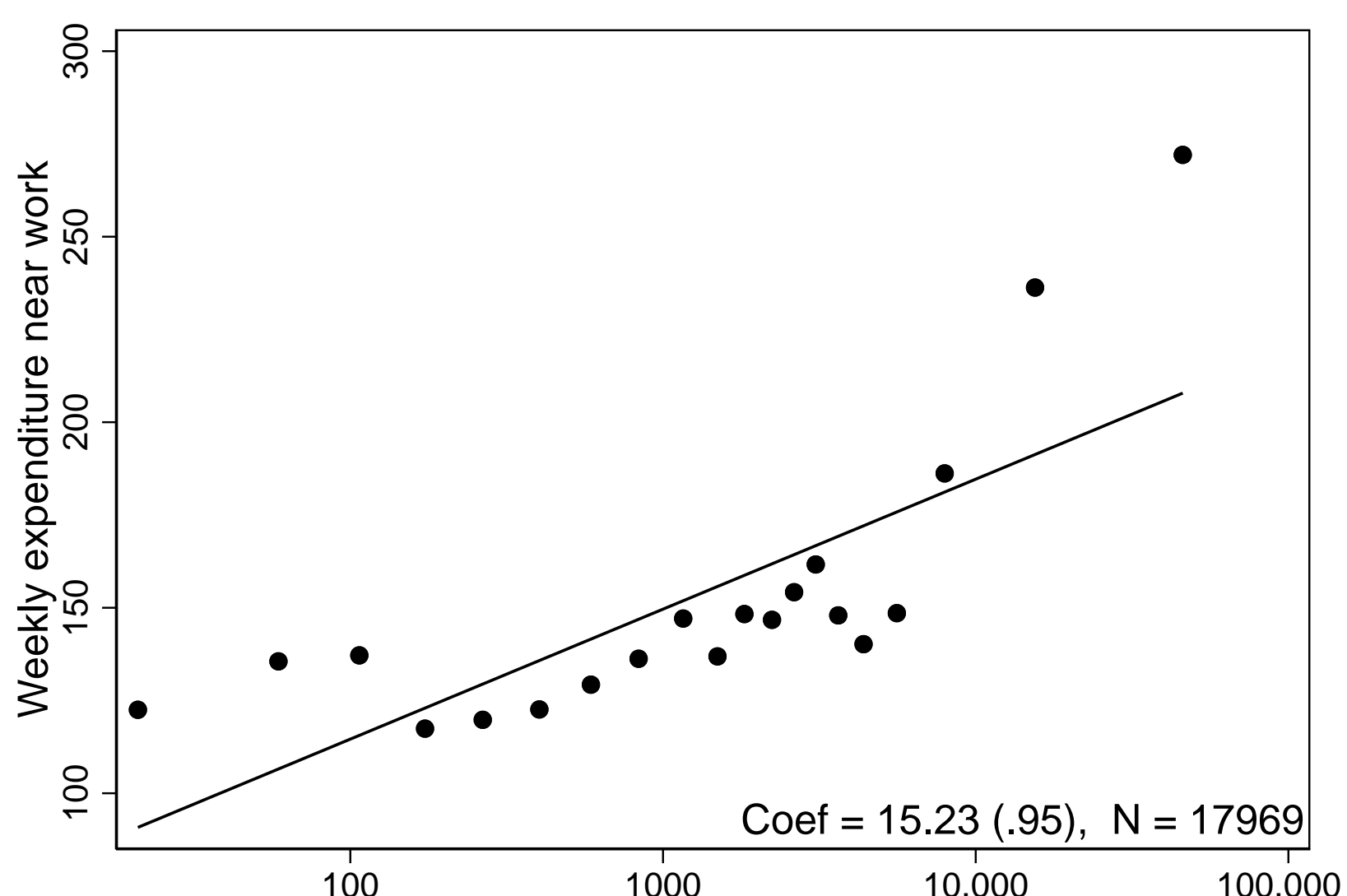

Population Density of Job Location, persons/sq. mile

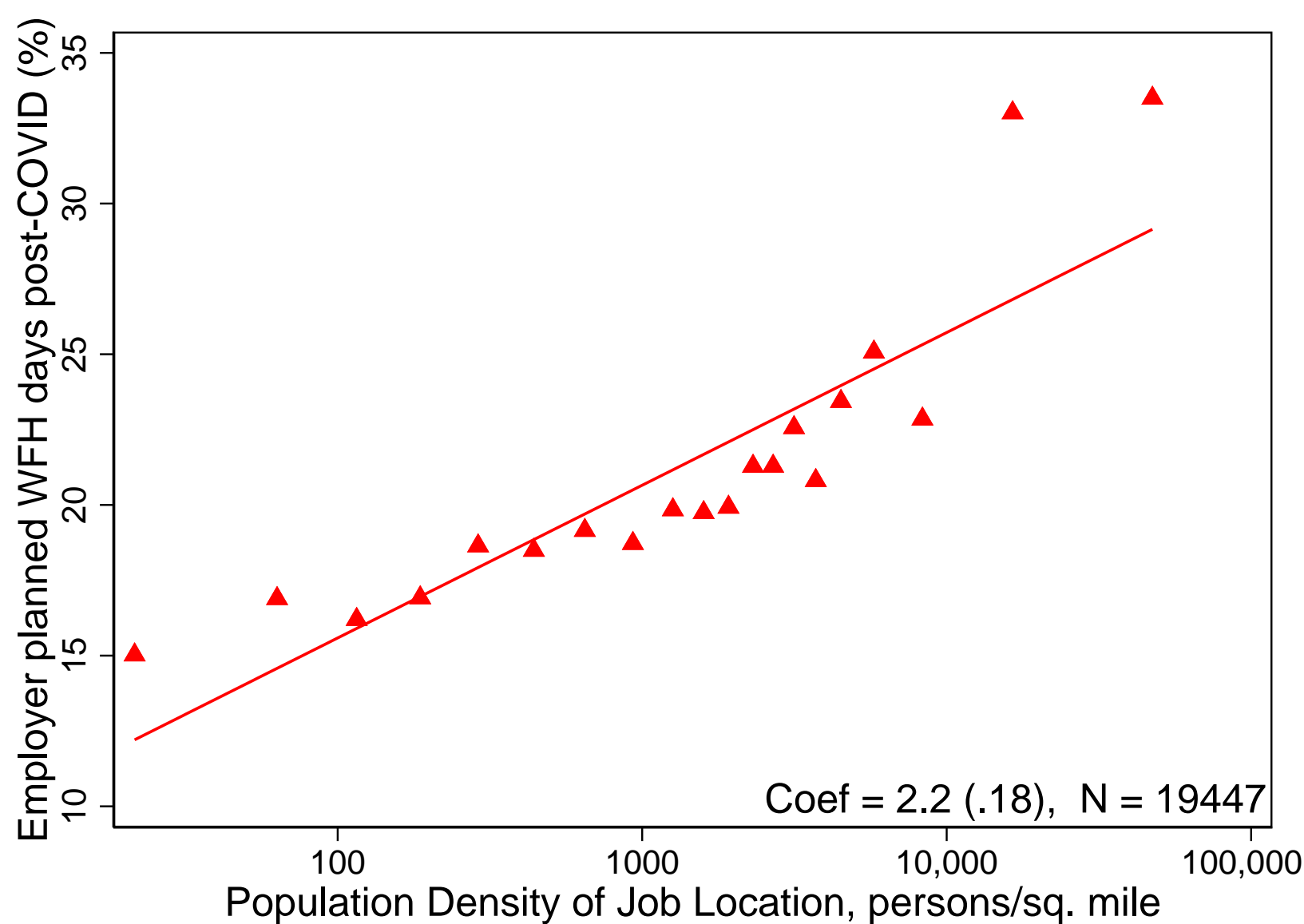

Source: Responses to the questions "In 2019, before COVID, in what ZIP code was your job located?", "In 2019, when you worked at your employer's business premises, roughly how much money did you spend during a typical day on food and drinks (e.g., lunch, coffee, snacks, etc.)?", and "In 2019, when you worked at your employer's business premises, roughly how much money did you spend during a typical week in bars, restaurants, and other entertainment venues that are near to your workplace?"

Notes: The left panel uses data from 22,500 survey responses collected from August 2020 to January 2021 by Inc-Query and QuestionPro. The right panel uses data from 28,250 responses collected from August 2020 to March 2021. We re-weight raw responses to match the share of working age respondents in the 2010-2019 CPS in a given \{age $x$ sex $x$ education $x$ earnings cell. 


\section{Figure 10: Efficiency of WFH vs. working on business premises}

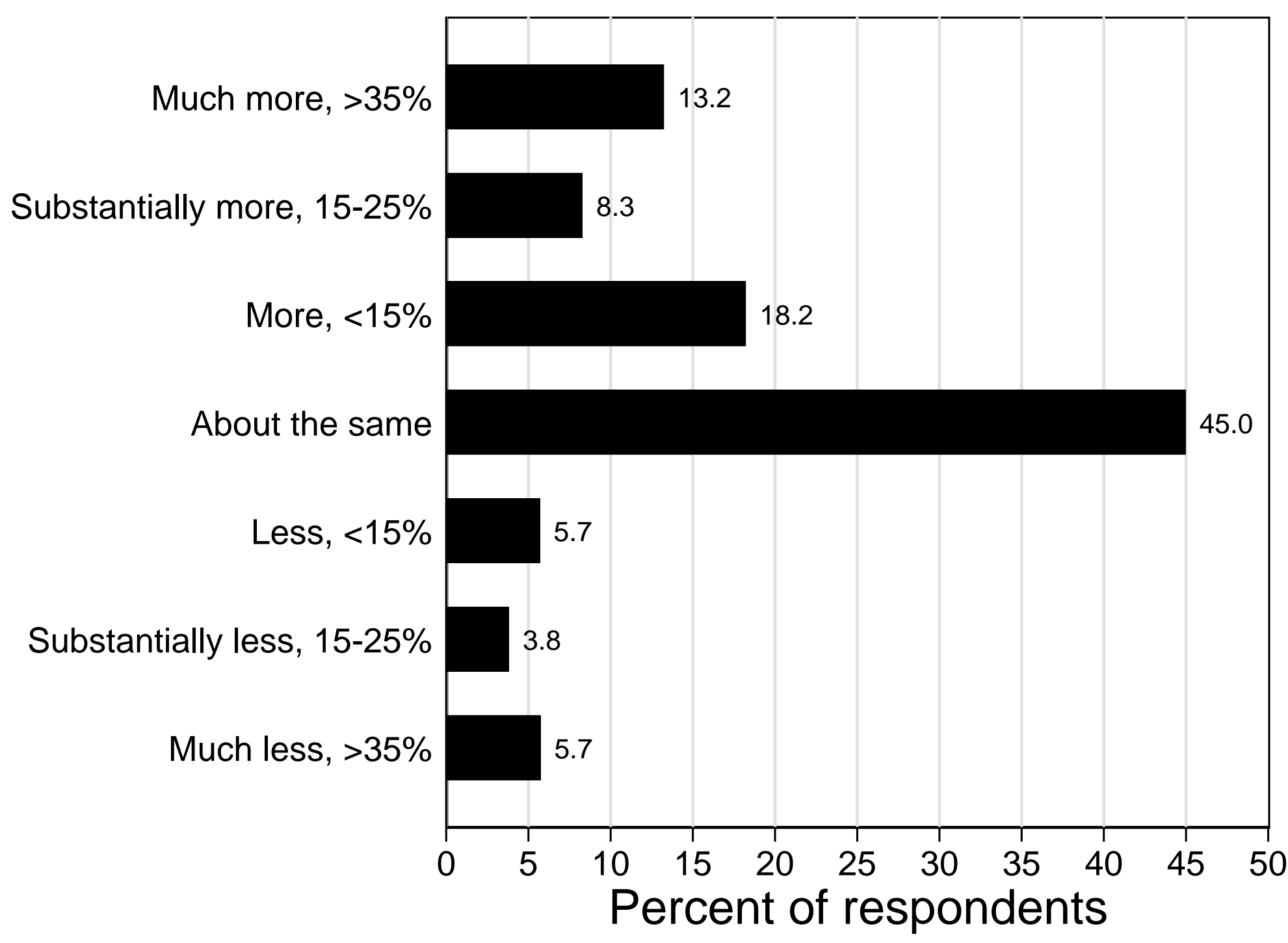

Source: Responses to the question:

"How does your efficiency working from home during the COVID-19 pandemic compare to your efficiency working on business premises before the pandemic?"

Notes: Data are from 28,250 survey responses collected from August 2020 to March 2021 by IncQuery and QuestionPro. We asked a similar question in earlier waves but focus on August 2020 to March 2021 when we kept the question and response options consistent. We re-weight raw responses to match the share of working age respondents in the 2010-2019 CPS in each age $x$ sex $x$ education $x$ earnings $\}$ cell. 
Table 1: Share of respondents mainly WFH during COVID-19

\begin{tabular}{|c|c|c|c|c|c|}
\hline Percent of respondents WFH during COVID & Estimate & $(\mathrm{SE})$ & Percent of respondents WFH during COVID & Estimate & $(\mathbf{S E})$ \\
\hline Overall & 32.5 & $(0.3)$ & Overall, ever WFH during COVID & 56.0 & $(0.3)$ \\
\hline Women & 33.6 & $(0.4)$ & Ann. Earnings of $\$ 20$ to $\$ 50 \mathrm{~K}$ & 24.2 & $(0.5)$ \\
\hline \multirow[t]{2}{*}{ Men } & 31.7 & $(0.4)$ & Ann. Earnings of $\$ 50$ to $\$ 100 \mathrm{~K}$ & 39.7 & $(0.5)$ \\
\hline & & & Ann. Earnings of $\$ 100$ to $\$ 150 \mathrm{~K}$ & 51.2 & $(0.7)$ \\
\hline Age 20 to 29 & 34.3 & $(0.7)$ & Ann. Earnings over $\$ 150 \mathrm{~K}$ & 55.4 & $(0.7)$ \\
\hline Age 30 to 39 & 36.6 & $(0.5)$ & & & \\
\hline Age 40 to 49 & 33.6 & $(0.5)$ & Goods-producing sectors & 24.4 & $(0.7)$ \\
\hline Age 50 to 64 & 27.6 & $(0.5)$ & Service sectors & 34.2 & $(0.3)$ \\
\hline Less than high school & 9.7 & $(1.9)$ & No children & 29.4 & $(0.4)$ \\
\hline High school & 19.4 & $(0.6)$ & Living with children under 18 & 34.8 & $(0.4)$ \\
\hline 1 to 3 years of college & 25.9 & $(0.5)$ & & & \\
\hline 4year college degree & 45.0 & $(0.5)$ & Red (Republican-leaning) state & 30.1 & $(0.4)$ \\
\hline Graduate degree & 50.2 & $(0.5)$ & Blue (Democratic-leaning) state & 34.7 & $(0.4)$ \\
\hline
\end{tabular}

Notes: Percent share of respondents who are working from home ("this week") during the COVID-19 pandemic, except the top right which estimates the share who "ever" worked from home during the pandemic. Data are from 33,250 survey responses collected from May 2020 to March 2021 by Inc-Query and QuestionPro. Until October 2020, we ask respondents whether they were primarily working from home, working on business premises, or not working. Since November 2020, we ask whether they are working and then how many full days they are working from home, and code the respondent as "working from home" if the WFH share exceeds 66 percent. We re-weight raw responses to match the share of working age respondents in the $2010-2019$ CPS in each age $\mathrm{x}$ sex $\mathrm{x}$ education $\mathrm{x}$ earnings \} cell. 


\section{Table 2: What predicts working from home during the COVID pandemic?}

Dependent Variable

(1)

(2)

(3)

(4)

$100 \times 1$ (Mainly WFH during COVID)

Years of education

$11.23 * * *$

(0.39)

$8.72 * * *$
$(0.43)$
$8.42 * * *$

$8.48 * * *$

(0.45)

1(Male)

1(Lives with children under 18)

1(Male) x 1(Lives with children under 18)

Biden vote share (state of residence)

Internet quality

Survey wave fixed effects

Age bin fixed effects

Industry Fixed Effects

Dependent variable mean

Observations

31.79

25,056

31.79

0.07

25,056

R-squared

Y

Y coefficients reflect a one-standard deviation change. Data are from 33,250 responses to match the share of working age respondents in the 2010-2019
$(0.43)$

$8.51 * * *$

$(0.47)$

$-2.67 * * *$

$(0.96)$

1.44

$(0.95)$

1.87

(1.44)

$8.42 * * *$
$(0.44)$
$8.29 * * *$
$(0.48)$
$-2.78 * * *$
$(0.96)$
1.55
$(0.95)$
1.70
$(1.44)$
$1.51 * * *$
$(0.36)$

$8.32 * * *$

(0.44)

$8.22 * * *$

$(0.48)$

$-2.87 * * *$

(0.96)

1.54

(0.95)

1.68

(1.44)

$1.47 * * *$

$(0.36)$

$1.57 * * *$

(0.37)

Y

Y

31.79

25,056

0.08
(6)

(7)

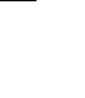

\begin{tabular}{ccc} 
& & \\
& $\mathrm{Y}$ & $\mathrm{Y}$ \\
& $\mathrm{Y}$ & $\mathrm{Y}$ \\
& & $\mathrm{Y}$ \\
31.79 & 31.79 & 31.79 \\
25,056 & 25,056 & 25,056 \\
0.09 & 0.09 & 0.12 \\
\hline
\end{tabular}

$8.00 * * * \quad 6.39 * * *$

$(0.43) \quad(0.46)$

$9.27 * * * \quad 8.12 * * *$

(0.48) (0.48)

$-3.40 * * * \quad-3.44 * * *$

(0.95) (0.96)

$-0.56 \quad-0.41$

$\begin{array}{ll}(0.98) & (0.97)\end{array}$

$\begin{array}{ll}1.76 & 0.68\end{array}$

(1.44) (1.41)

$1.34 * * * \quad 1.23 * * *$

(0.36) (0.35)

$1.52 * * * \quad 1.26 * * *$

(0.37) (0.37) 
Table 3: Worker desires for WFH are fairly uniform. Employer plans are not.

\begin{tabular}{|c|c|c|c|c|c|c|c|c|c|}
\hline $\begin{array}{l}\text { Percent share of paid WFH } \\
\text { days post-COVID }\end{array}$ & $\begin{array}{l}\text { Worker } \\
\text { desired }\end{array}$ & (SE) & $\begin{array}{c}\text { Employer } \\
\text { planned }\end{array}$ & (SE) & $\begin{array}{l}\text { Percent share of paid WFH days } \\
\text { post-COVID }\end{array}$ & $\begin{array}{l}\text { Worker } \\
\text { desired }\end{array}$ & (SE) & $\begin{array}{l}\text { Employer } \\
\text { planned }\end{array}$ & (SE) \\
\hline Overall & 45.5 & $(0.3)$ & 21.3 & $(0.2)$ & & & & & \\
\hline Women & 48.7 & $(0.4)$ & 18.9 & $(0.3)$ & Ann. Earnings of $\$ 20$ to $\$ 50 \mathrm{~K}$ & 43.4 & $(0.5)$ & 15.9 & $(0.4)$ \\
\hline \multirow[t]{2}{*}{ Men } & 43.1 & $(0.4)$ & 23.1 & $(0.3)$ & Ann. Earnings of $\$ 50$ to $\$ 100 \mathrm{~K}$ & 46.9 & $(0.4)$ & 24.8 & $(0.4)$ \\
\hline & & & & & Ann. Earnings of $\$ 100$ to $\$ 150 \mathrm{~K}$ & 50.1 & $(0.6)$ & 33.6 & $(0.6)$ \\
\hline Age 20 to 29 & 46.9 & $(0.6)$ & 23.9 & $(0.6)$ & Ann. Earnings over $\$ 150 \mathrm{~K}$ & 53.3 & $(0.6)$ & 41.5 & $(0.7)$ \\
\hline Age 30 to 39 & 48.7 & $(0.5)$ & 24.9 & $(0.4)$ & & & & & \\
\hline Age 40 to 49 & 46.0 & $(0.5)$ & 21.3 & $(0.5)$ & Goods-producing sectors & 40.5 & $(0.7)$ & 18.7 & $(0.6)$ \\
\hline Age 50 to 64 & 41.4 & $(0.6)$ & 16.5 & $(0.4)$ & Service sectors & 46.6 & $(0.3)$ & 21.9 & $(0.3)$ \\
\hline Less than high school & 40.7 & $(3.2)$ & 12.6 & $(2.3)$ & No children & 44.4 & $(0.4)$ & 17.8 & $(0.3)$ \\
\hline High school & 37.9 & $(0.7)$ & 15.2 & $(0.6)$ & Living with children under 18 & 47.3 & $(0.4)$ & 25.4 & $(0.3)$ \\
\hline 1 to 3 years of college & 45.6 & $(0.6)$ & 17.3 & $(0.5)$ & & & & & \\
\hline 4-year college degree & 50.5 & $(0.5)$ & 26.4 & $(0.5)$ & Red (Republican-leaning) State & 44.8 & $(0.4)$ & 20.5 & $(0.4)$ \\
\hline Graduate degree & 49.2 & $(0.4)$ & 30.4 & $(0.4)$ & Blue (Democratic-leaning) State & 46.1 & $(0.4)$ & 22.0 & $(0.3)$ \\
\hline
\end{tabular}

Notes: Average percent of full paid working days workers desire and employers plan to be spent working from home post-COVID, by group. Data are from 30,750 survey responses collected from July 2020 to March 2021 by Inc-Query and QuestionPro. We exclude workers who claim to have "no employer" in the employer plans question and impute zero employer planned working days for respondents who have not received any clear indication from their employer. We re-weight raw responses to match the share of working age respondents in the 2010-2019 CPS in a given \{age $\mathrm{x}$ sex $\mathrm{x}$ education $\mathrm{x}$ earnings cell. This table excludes data from the May 2020 wave because we didn't ask about post-COVID employer plans that month. 


\section{Table 4: Residual fear of proximity to other people}

Once most of the population has been vaccinated against COVID, which of the following would best fit your views on social distancing?

Substantial return to pre-COVID activities, but I would still be wary of things

like riding the subway or getting into a crowded elevator

Partial return to pre-COVID activities, but I would be wary of many activities like eating out or using ride-share taxis

\section{Observations}

Notes: The table shows the response distribution to the question, "Once most of the population has been vaccinated against COVID, which of the following would best fit your views on social distancing?" The latter is the question wording as of March 2021, but we have updated the precise wording as vaccine developments have taken place during the pandemic. Data are from 31,750 survey responses collected from July 2020 to March 2021 by Inc-Query and QuestionPro. We re-weight raw responses to match the share of working age respondents in the 2010-2019 CPS in each \{age x sex x education x earnings\} cell. 
Table 5: Working from home is a valuable perk. The benefits of a shift towards WFH are unevenly distributed across demographic groups

\begin{tabular}{|c|c|c|c|c|c|c|c|c|c|}
\hline $\begin{array}{l}\text { Percent share of paid } \\
\text { WFH days post-COVID }\end{array}$ & $\begin{array}{c}\text { Value of planned } \\
\text { post-COVID } \\
\text { WFH, \% earnings }\end{array}$ & (SE) & $\begin{array}{l}\text { Perk value of the } \\
\text { option to WFH, } \\
\% \text { earnings }\end{array}$ & (SE) & $\begin{array}{l}\text { Percent share of paid WFH days } \\
\text { post-COVID }\end{array}$ & $\begin{array}{l}\text { Value of } \\
\text { planned post- } \\
\text { COVID WFH, } \\
\text { \% earnings }\end{array}$ & (SE) & $\begin{array}{c}\text { Perk value of } \\
\text { the option to } \\
\text { WFH, \% } \\
\text { earnings }\end{array}$ & (SE) \\
\hline Overall & 2.5 & $(0.1)$ & 7.2 & $(0.1)$ & & & & & \\
\hline Women & 2.0 & $(0.1)$ & 7.6 & $(0.1)$ & Ann. Earnings of $\$ 20$ to $\$ 50 \mathrm{~K}$ & 1.7 & $(0.1)$ & 6.6 & $(0.2)$ \\
\hline \multirow[t]{2}{*}{ Men } & 2.9 & $(0.1)$ & 6.9 & $(0.1)$ & Ann. Earnings of $\$ 50$ to $\$ 100 \mathrm{~K}$ & 2.8 & $(0.1)$ & 7.2 & $(0.1)$ \\
\hline & & & & & Ann. Earnings of $\$ 100$ to $\$ 150 \mathrm{~K}$ & 4.5 & $(0.2)$ & 8.7 & $(0.2)$ \\
\hline Age 20 to 29 & 2.8 & $(0.1)$ & 8.2 & $(0.2)$ & Ann. Earnings over $\$ 150 \mathrm{~K}$ & 6.8 & $(0.2)$ & 11.7 & $(0.2)$ \\
\hline Age 30 to 39 & 3.0 & $(0.1)$ & 8.4 & $(0.2)$ & & & & & \\
\hline Age 40 to 49 & 2.6 & $(0.1)$ & 7.6 & $(0.2)$ & Goods-producing sectors & 2.4 & $(0.1)$ & 6.2 & $(0.2)$ \\
\hline Age 50 to 64 & 1.7 & $(0.1)$ & 5.1 & $(0.2)$ & $\underline{\text { Service sectors }}$ & 2.5 & $(0.1)$ & 7.4 & $(0.1)$ \\
\hline Less than high school & 2.5 & $(0.6)$ & 5.7 & (1.1) & No children & 1.9 & $(0.1)$ & 6.1 & $(0.1)$ \\
\hline High school & 1.7 & $(0.1)$ & 5.6 & $(0.3)$ & Living with children under 18 & 3.2 & $(0.1)$ & 8.4 & $(0.1)$ \\
\hline 1 to 3 years of college & 1.8 & $(0.1)$ & 6.7 & $(0.2)$ & & & & & \\
\hline 4year college degree & 3.0 & $(0.1)$ & 7.9 & $(0.1)$ & Red (Republican-leaning) State & 2.3 & $(0.1)$ & 7.2 & $(0.1)$ \\
\hline Graduate degree & 4.0 & $(0.1)$ & 9.5 & $(0.1)$ & Blue (Democratic-leaning) State & 2.7 & $(0.1)$ & 7.2 & $(0.1)$ \\
\hline
\end{tabular}

Notes: The "value of planned WFH" is equal to the "perk value of WFH" 2 to 3 days per week, adjusted to reflect employer plans. The "perk value of WFH" is based responses to the following two-part question: Part 1: "After COVID, in 2022 and later, how would you feel about working from home 2 or 3 days a week?" Part 2: "How much of a pay raise [cut] (as a percent of your current pay) would you value as much as the option to work from home 2 or 3 days a week?". See the text for details. Data are from 28,250 survey responses collected from July 2020 to February 2021 by Inc-Query and QuestionPro. We re-weight raw responses to match the share of working age respondents in the 2010-2019 CPS in a given \{age $\mathrm{x}$ sex x education $\mathrm{x}$ earnings cell. 
Appendix A

Additional tables and figures 


\section{Figure A.1 Sample survey questions}

6. After COVID, in 2022 and later, how often is your employer planning for you to work full days at home?

Never

About once or twice per month

1 day per week

2 days per week

3 days per week

4 days per week

$5+$ days per week

My employer has not discussed this matter with me or announced a policy about it

I have no employer

Auto-fill Re-randomize
31. Compared to your expectations before COVID (in 2019) how has working from home turned out for you?

Hugely better -- I am $20 \%+$ more productive than I expected

Substantially better -- I am to $10 \%$ to $19 \%$ more productive than I expected

Better - I am $1 \%$ to $9 \%$ more productive than I expected

About the same

Worse -- I am $1 \%$ to $9 \%$ less productive than I expected

Substantially worse -- I am to $10 \%$ to $19 \%$ less productive than I expected

Hugely worse -- I am $20 \%+$ less productive than I expected 
Figure A.2 Higher income workers have longer commutes

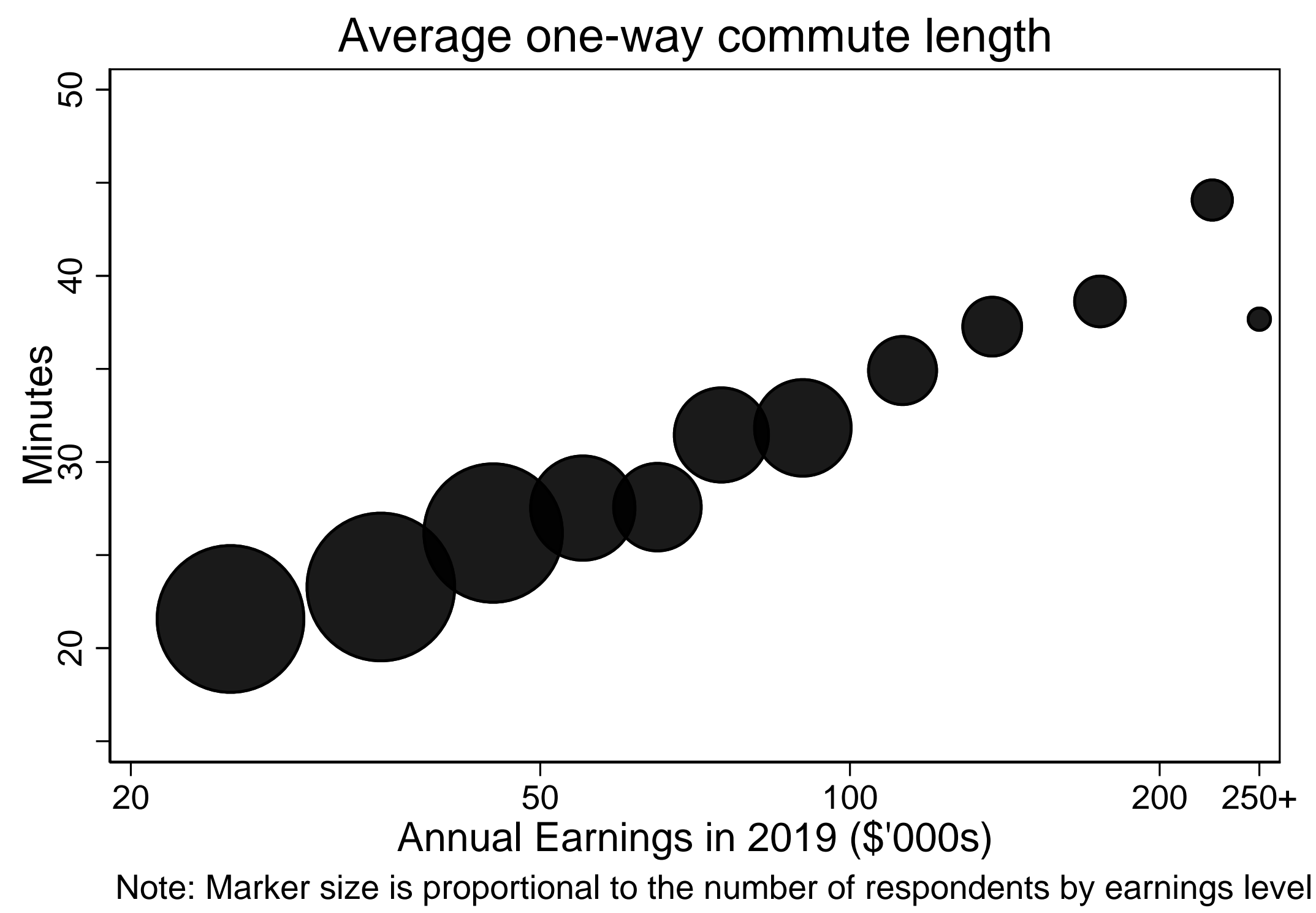

Source: Responses to the questions:

In 2019 (before COVID) how long was your typical commute to work in minutes?

How much did you earn by working in $2019 ?$

Notes: The figure shows the average one-way commute time as a function of reported earnings in 2019. Data are from 23,250 survey responses collected between May 2020 and March 2021 by Inc-Query and QuestionPro. We did not ask about commuting time in December 2020 or January 2021. We reweight raw responses to match the share of working age respondents in the 2010-2019 CPS in each ange $x$ sex $x$ education $x$ earnings $\}$ cell. Marker sizes are proportional to the weighted number of respondents. 


\section{Figure A.3 Desired post-COVID WFH days by sex among the college-educated}

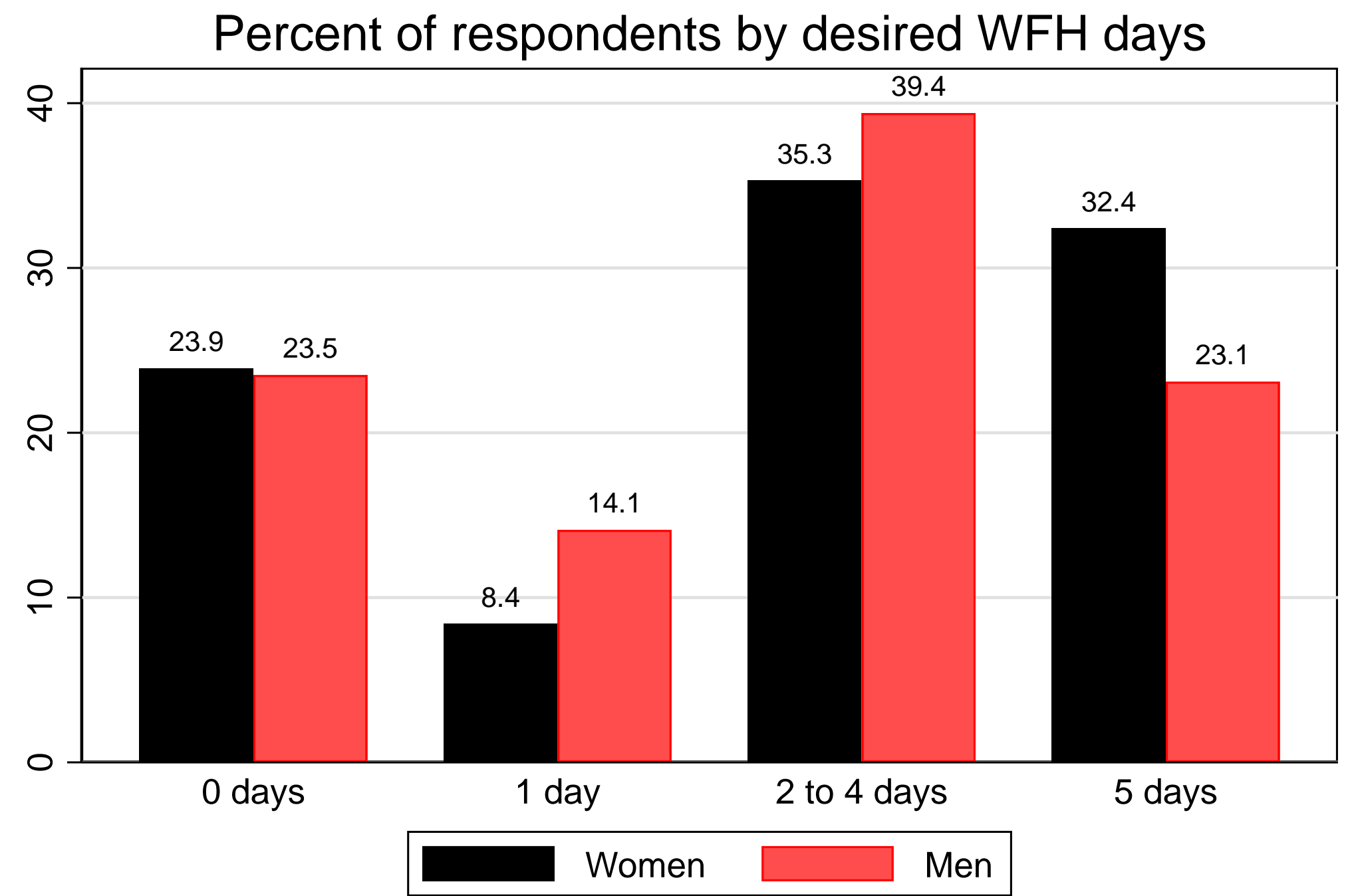

Source: Responses to the question:

After COVID, in 2022 and later, how often would you like to have paid workdays at home?

Notes: Data are from 30,750 survey responses collected from July 2020 to March 2021 by Inc-Query and QuestionPro. The sample includes respondents with at least some college ( 1 to 3 years of college or more) who live with children under 12 years old. In July and August 2020 we did not collect child ages and instead asked whether the youngest child in the household is in High School, Elementary School, etc. We assume children are under 12 if they are in Elementary School or lower in those months.

Sample: Respondents with at least some college and children under 12 
Figure A.4 Self-assessed efficiency of WFH during COVID rises with WFH during COVID and desires and plans for post-COVID WFH

During COVID: Percent of respondents mainly WFH

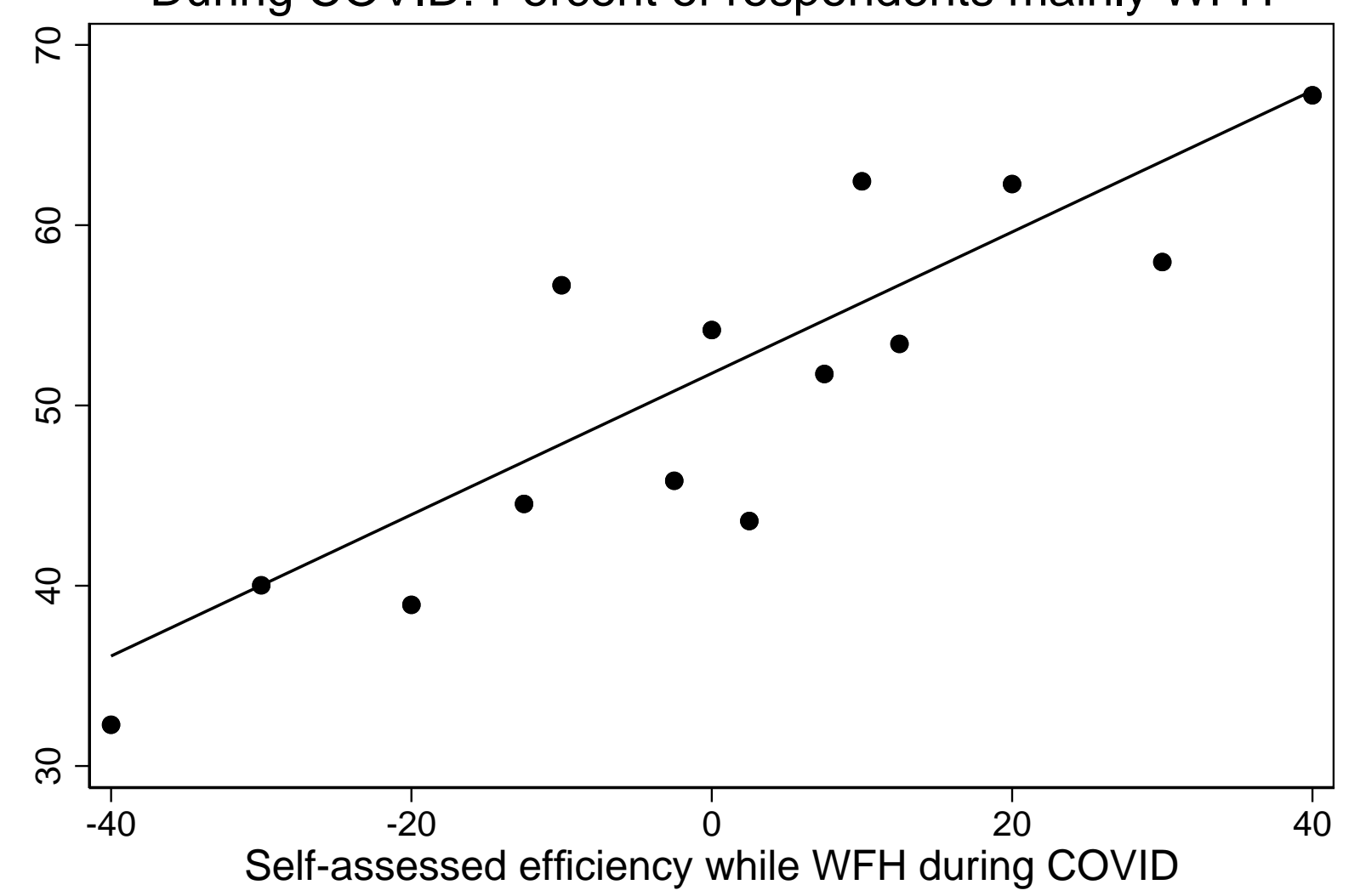

Post-COVID: Percent of full workdays at home

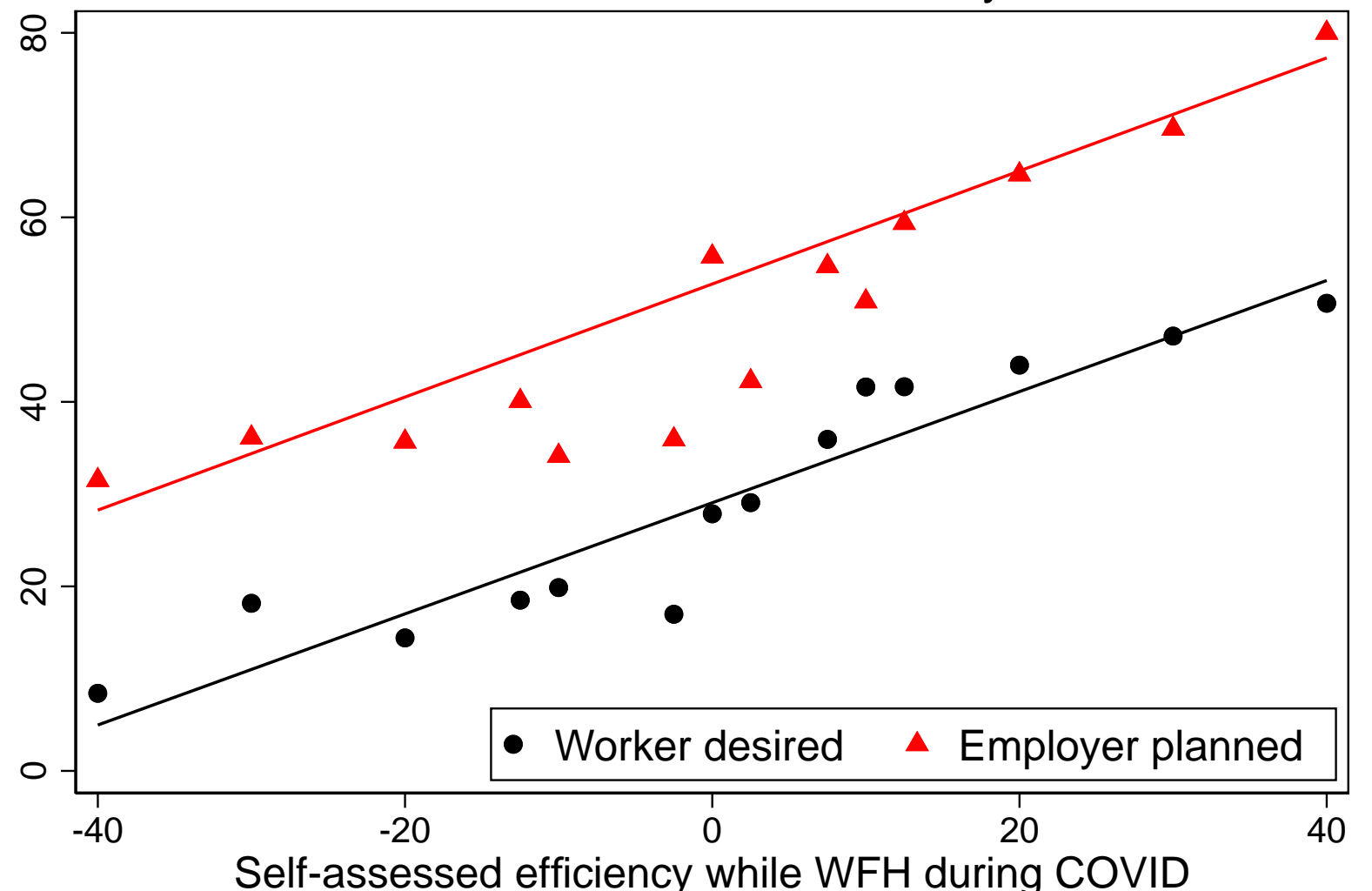

Source: Responses to the questions: "After COVID, in 2022 and later, how often would you like to have paid workdays at home?", "After COVID, in 2022 and later, how often is your employer planning for you to work full days at home?", "How does your efficiency working from home during the COVID-19 pandemic compare to your efficiency working on business premises before the pandemic?" and questions about current working status.

Notes: The figure on the left shows a binscatter of an indicator for the respondent mainly working from home at the time of the survey (self-reported before November 2020, and since then if they worked from home at least 66 percent of working days in the survey week) against self-assessed relative efficiency of WFH. The figure on the right shows binscatters for the amount of worker-desired and employer-planned WFH post-COVID. Data are from 28,250 survey responses collected from August 2020 to March 2021 by Inc-Query and QuestionPro. We re-weight raw responses to match the share of working-age respondents in the 2010-2019 CPS in each \{age $x$ sex $x$ education $x$ earnings cell. 


\section{Table A.1 Summary statistics}

\begin{tabular}{|c|c|c|c|c|c|c|}
\hline Variable & Mean & SD & $25 p$ & 50p & $75 p$ & $\mathbf{N}$ \\
\hline Earnings, $\$$ '000s & 63.1 & 73.5 & 35 & 45 & 75 & 28,597 \\
\hline Age & 43.0 & 11.6 & 35 & 45 & 57 & 28,597 \\
\hline Years of education & 14.5 & 2.4 & 12 & 14 & 16 & 28,597 \\
\hline $100 * 1$ (Ever WFH during COVID?) & 56.0 & 49.6 & 0 & 100 & 100 & 23,503 \\
\hline $100 * 1$ (Currently WFH during COVID) & 32.5 & 46.8 & 0 & 0 & 100 & 28,597 \\
\hline Percent worker desired post-COVID WFH days & 45.7 & 41.0 & 0 & 40 & 100 & 28,597 \\
\hline Percent employer planned post-COVID WFH days & 21.3 & 35.6 & 0 & 0 & 40 & 22,720 \\
\hline Commute time pre-COVID (minutes) & 27.1 & 26.4 & 10 & 20 & 35 & 20,554 \\
\hline Percent raise equal to option to WFH 2-3 days/week & 7.0 & 12.5 & 0 & 5 & 13 & 25,232 \\
\hline How much more productive than expected has WFH been? & 7.1 & 13.0 & 0 & 5 & 15 & 16,309 \\
\hline Can you do your job from home ( 0 to $100 \%$ scale) & 50.4 & 48.9 & 0 & 57 & 90 & 22,086 \\
\hline Percent higher effectiveness WFH during COVID over business premises pre-COVID & 4.5 & 17.2 & 0 & 0 & 13 & 16,611 \\
\hline Investments in infrastructure, equipment for WFH by employer or self, $\$$ & 561.1 & 1086.4 & 0 & 100 & 500 & 13,642 \\
\hline Hours invested learning to WFH effectively & 14.9 & 24.2 & 2 & 7 & 20 & 13,658 \\
\hline Weekly spending near work, \$ & 151.9 & 163.9 & 35 & 100 & 200 & 20,578 \\
\hline 1(Female) & 43.8 & 49.6 & 0 & 0 & 100 & 28,597 \\
\hline 1(Red State) & 47.6 & 49.9 & 0 & 0 & 100 & 28,597 \\
\hline
\end{tabular}

Notes: Summary statistics for key variables, re-weighted to match the share of people in the 2010-2019 CPS in a given \{age x sex x education x earnings\} cell. Data are from 33,250 survey responses collected between May 2020 and March 2021 by Inc-Query and QuestionPro. We re-weight raw responses to match the share of working age respondents in the 2010-2019 CPS in each \{industry x state x earnings\} cell. Not all questions (and hence not all variables) appear in all waves. Number of observations is less than the 33,250 survey responses primarily due to dropping responses that took less than 2 minutes in May, less than 3 minutes in the July to November 2020 waves, and less than 5 minutes in the December 2020 to March 2021 waves. 


\section{Using the ATUS to estimate the extent of WFH before the pandemic}

We supplement our data collection efforts with published data from the Job Flexibilities and Work Schedules module of the American Time Use Survey (ATUS). This survey module ran continuously in 2017 and 2018, yielding about 10,000 responses from wage and salary workers.

According to the tabulations at https:/www.bls.gov/news.release/flex2.t03.htm, only 14.7 percent of employees performed any full workdays from home before the pandemic. Among those who did, the frequency distribution of full WFH days is as follows: Less than once a month $(18.4 \%)$, once a month $(13.5 \%)$, once every two weeks (13.1\%), at least 1 day per week (10.2\%), 1 to 2 days per week (17.4\%), 3 to 4 days per week $(12.8 \%)$, and 5 or more days per week $(14.5 \%)$. Thus, we estimate the share of full workdays at home before the pandemic as 4.8 percent, computed as 100 times $[0 *(1-.147)+.147 *(0 * 0.184+0.05 * .135+$ $0.1 * .131+0.2 * .102+0.3 * .174+0.7 * .128+1 * .145)]$. We plot this $4.8 \%$ figure as the leftmost data point in the right panel of Figure 1. The full survey is at https://www.bls.gov/news.release/flex2.nr0.htm. 
Table A.2 Working-from-Home Productivity during COVID relative to expectations

\begin{tabular}{|c|c|c|c|c|c|}
\hline $\begin{array}{l}\text { Percent difference between WFH productivity and } \\
\text { expectations }\end{array}$ & Mean & (SE) & $\begin{array}{l}\text { Percent difference between WFH } \\
\text { productivity and expectations }\end{array}$ & Mean & (SE) \\
\hline Overall & 7.1 & $(0.1)$ & & & \\
\hline Women & 6.9 & $(0.2)$ & Ann. Earnings of $\$ 20$ to $\$ 50 \mathrm{~K}$ & 6.0 & $(0.2)$ \\
\hline \multirow[t]{2}{*}{ Men } & 7.4 & $(0.1)$ & Ann. Earnings of $\$ 50$ to $\$ 100 \mathrm{~K}$ & 7.5 & $(0.2)$ \\
\hline & & & Ann. Earnings of $\$ 100$ to $\$ 150 \mathrm{~K}$ & 9.0 & $(0.2)$ \\
\hline Age 20 to 29 & 7.3 & $(0.2)$ & Ann. Earnings over $\$ 150 \mathrm{~K}$ & 10.4 & $(0.2)$ \\
\hline Age 30 to 39 & 8.1 & $(0.2)$ & & & \\
\hline Age 40 to 49 & 7.4 & $(0.2)$ & Goods-producing sectors & 7.8 & $(0.3)$ \\
\hline Age 50 to 64 & 5.7 & $(0.2)$ & $\underline{\text { Service sectors }}$ & 7.0 & $(0.1)$ \\
\hline Less than high school & 6.6 & $(1.6)$ & No children & 6.0 & $(0.2)$ \\
\hline High school & 5.8 & $(0.4)$ & Living with children under 18 & 8.3 & $(0.1)$ \\
\hline 1 to 3 years of college & 6.5 & $(0.2)$ & & & \\
\hline 4year college degree & 7.3 & $(0.2)$ & Red (Republican-leaning) state & 7.1 & $(0.2)$ \\
\hline Graduate degree & 8.5 & $(0.2)$ & Blue (Democratic-leaning) state & 7.1 & $(0.1)$ \\
\hline
\end{tabular}

Notes: This table computes the average percent difference between productivity while working from home during COVID and expected WFH productivity prior to the pandemic. The underlying survey question asks "Compared to your expectations before COVID (in 2019) how has working from home turned out for you?" Data are from 30,750 survey responses collected between July 2020 and March 2021 by QuestionPro and IncQuery. We reweight raw responses to match the share of working age respondents in the 2010-2019 CPS in a given \{age $\mathrm{x}$ sex $\mathrm{x}$ education $\mathrm{x}$ earnings $\}$ cell. 


\section{Table A.3 Investments that enable working from home}

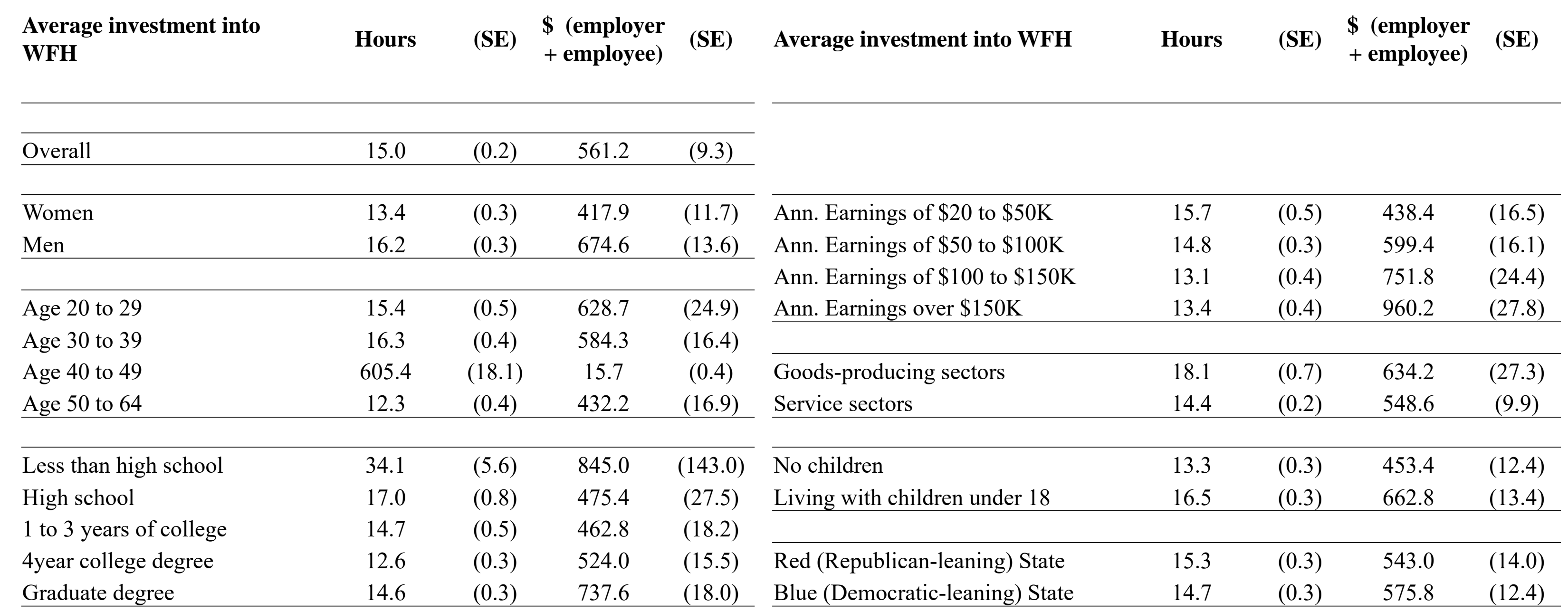

Notes: Average number of hours and dollars (paid by employer or employee) invested in enabling work from home during the pandemic. Data are from 30,750 survey responses collected from July 2020 to March 2021 by Inc-Query and QuestionPro. We did not ask about the investments enabling WFH during COVID in May 202. We reweight raw responses to match the share of working age respondents in the 2010-2019 CPS in a given \{age $\mathrm{x}$ sex $\mathrm{x}$ education $\mathrm{x}$ earnings\} cell. 


\section{Table A.4 The stigma of working from home has diminished}

\begin{tabular}{|c|c|c|c|c|c|c|c|c|c|}
\hline Percent of respondents & $\begin{array}{c}\text { Net change in } \\
\text { WFH } \\
\text { perception }\end{array}$ & (SE) & $\begin{array}{c}\text { Positive } \\
\text { change in } \\
\text { WFH } \\
\text { perception }\end{array}$ & (SE) & Percent of respondents & $\begin{array}{c}\text { Net change in } \\
\text { WFH } \\
\text { perception }\end{array}$ & (SE) & $\begin{array}{c}\text { Positive change } \\
\text { in WFH } \\
\text { perception }\end{array}$ & $(\mathbf{S E})$ \\
\hline Overall & 58.6 & $(0.4)$ & 65.1 & $(0.3)$ & & & & & \\
\hline Women & 58.5 & $(0.6)$ & 65.4 & $(0.4)$ & Ann. Earnings of $\$ 20$ to $\$ 50 \mathrm{~K}$ & 54.0 & $(0.7)$ & 60.9 & $(0.6)$ \\
\hline Men & 58.6 & $(0.5)$ & 64.9 & $(0.4)$ & Ann. Earnings of $\$ 50$ to $\$ 100 \mathrm{~K}$ & 62.1 & $(0.6)$ & 68.4 & $(0.5)$ \\
\hline Age 20 to 29 & 62.4 & $(1.0)$ & 69.6 & $(0.7)$ & $\begin{array}{l}\text { Ann. Earnings of } \$ 100 \text { to } \\
\$ 150 \mathrm{~K} \\
\text { Ann. Earnings over } \$ 150 \mathrm{~K}\end{array}$ & $\begin{array}{l}70.1 \\
74.7\end{array}$ & $\begin{array}{l}(0.9) \\
(0.9)\end{array}$ & $\begin{array}{l}75.7 \\
80.8\end{array}$ & $\begin{array}{l}(0.6) \\
(0.6)\end{array}$ \\
\hline Age 30 to 39 & 64.6 & $(0.7)$ & 70.6 & $(0.5)$ & & & & & \\
\hline Age 40 to 49 & 58.4 & $(0.7)$ & 65.1 & $(0.6)$ & Goods-producing sectors & 54.5 & $(1.0)$ & 61.5 & $(0.8)$ \\
\hline Age 50 to 64 & 52.0 & $(0.7)$ & 58.5 & $(0.6)$ & Service sectors & 59.4 & $(0.4)$ & 65.9 & $(0.3)$ \\
\hline Less than high school & 50.7 & $(4.1)$ & 56.6 & $(3.4)$ & No children & 54.9 & $(0.6)$ & 63.1 & $(0.5)$ \\
\hline High school & 45.5 & $(1.0)$ & 52.6 & $(0.8)$ & Living with children under 18 & 61.5 & $(0.5)$ & 69.7 & $(0.4)$ \\
\hline 1 to 3 years of college & 56.0 & $(0.8)$ & 62.9 & $(0.6)$ & & & & & \\
\hline 4-year college degree & 66.4 & $(0.7)$ & 72.5 & $(0.5)$ & Red (Republican-leaning) state & 57.8 & $(0.6)$ & 64.1 & $(0.5)$ \\
\hline Graduate degree & 72.7 & $(0.6)$ & 78.8 & $(0.5)$ & Blue (Democratic-leaning) state & 59.2 & $(0.5)$ & 66.1 & $(0.4)$ \\
\hline
\end{tabular}

Notes: This table reports (1) the net change in perceptions about working from home, equal to the percent of respondents who report WFH perceptions have improved among some, most, or almost all the "people they know" minus the percent who report they have worsened; (2) the percent of respondents who report perceptions of WFH have improved among people they know. Data are from 30,750 survey responses collected from July 2020 to March 2021 by Inc-Query and QuestionPro. We reweight raw responses to match the share of working age respondents in the 2010-2019 CPS in a given \{age x sex x education x earnings\} cell. 


\section{Table A.5 Residual fear of proximity to other people}

\begin{tabular}{|c|c|c|c|c|c|}
\hline $\begin{array}{l}\text { Percent of workers who would return to pre-COVID } \\
\text { activities "completely" }\end{array}$ & Mean & (SE) & $\begin{array}{l}\text { Percent of workers who would return to } \\
\text { pre-COVID activities "completely" }\end{array}$ & Mean & (SE) \\
\hline Overall & 28.4 & $(0.3)$ & & & \\
\hline Women & 21.1 & $(0.4)$ & Ann. Earnings of $\$ 20$ to $\$ 50 \mathrm{~K}$ & 26.0 & $(0.5)$ \\
\hline \multirow[t]{2}{*}{ Men } & 34.2 & $(0.4)$ & Ann. Earnings of $\$ 50$ to $\$ 100 \mathrm{~K}$ & 29.3 & $(0.5)$ \\
\hline & & & Ann. Earnings of $\$ 100$ to $\$ 150 \mathrm{~K}$ & 36.2 & $(0.7)$ \\
\hline Age 20 to 29 & 26.8 & $(0.7)$ & Ann. Earnings over $\$ 150 \mathrm{~K}$ & 42.1 & $(0.8)$ \\
\hline Age 30 to 39 & 30.2 & $(0.5)$ & & & \\
\hline Age 40 to 49 & 31.2 & $(0.6)$ & Goods-producing sectors & 37.4 & $(0.8)$ \\
\hline Age 50 to 64 & 25.8 & $(0.5)$ & Service sectors & 26.6 & $(0.3)$ \\
\hline Less than high school & 35.8 & $(3.3)$ & No children & 25.6 & $(0.4)$ \\
\hline High school & 30.5 & $(0.8)$ & Living with children under 18 & 32.0 & $(0.4)$ \\
\hline 1 to 3 years of college & 25.5 & $(0.6)$ & & & \\
\hline 4year college degree & 25.1 & $(0.5)$ & Red (Republican-leaning) state & 28.2 & $(0.4)$ \\
\hline Graduate degree & 34.1 & $(0.5)$ & Blue (Democratic-leaning) state & 28.6 & $(0.4)$ \\
\hline
\end{tabular}

Notes: This table reports the percent share of workers who would return to pre-COVID activities "completely" if a vaccine is found and made widely available. Data are from 30,750 survey responses collected from July 2020 to March 2021 by Inc-Query and QuestionPro. We re-weight raw responses to match the share of working age respondents in the 2010-2019 CPS in a given \{age $\mathrm{x}$ sex $\mathrm{x}$ education $\mathrm{x}$ earnings\} cell. 


\section{Table A.6: Residual fear of proximity to other people (reasons cited)}

You have stated that you would not return completely to pre-COVID activities, if a COVID vaccine is discovered and made widely available. What reasons are behind your answer? Please check all that apply

I am concerned about the effectiveness/safety/that not enough people will take the COVID vaccine

Notes: Data are from 7,500 survey responses collected in September, October, and November 2020 by Inc-Query and QuestionPro. Each wave collected 2,500 responses, but we only asked this question if the respondent stated they would not return "completely" to pre-COVID activities in the event a vaccine was discovered and made widely available. We reweight raw responses to match the share of working age respondents in the 2010-2019 CPS in a given age $\mathrm{x}$ sex $\mathrm{x}$ education $\mathrm{x}$ earnings $\}$ cell. 
Table A.7. Employer plans and employee desires for post-COVID WFH correlate positively with improved perceptions of WFH

\begin{tabular}{|c|c|c|c|c|c|}
\hline \multirow[b]{2}{*}{ Perceptions about WFH } & \multicolumn{4}{|c|}{ Percent WFH days post-COVID (SE) } & \multirow[b]{2}{*}{$\mathbf{N}$} \\
\hline & Emplo & desired & Empla & lanned & \\
\hline Improved among almost all (90 to $100 \%)$ & 56.8 & $(0.5)$ & 30.9 & $(0.5)$ & 6955 \\
\hline Improved among most & 49.8 & $(0.5)$ & 23.4 & $(0.4)$ & 7442 \\
\hline Improved among some & 43.2 & $(0.7)$ & 19.7 & $(0.6)$ & 3540 \\
\hline No change & 34.9 & $(0.6)$ & 12.3 & $(0.4)$ & 5480 \\
\hline Worsened & 40.7 & $(1.1)$ & 20.6 & $(0.9)$ & 1585 \\
\hline \multicolumn{6}{|c|}{$\begin{array}{l}\text { Notes: This table estimates the percent share of days spent working from home post-COVID desired by workers } \\
\text { and planned by their employers, as a function of how the employee believes perceptions about working from } \\
\text { home have changed since the onset of the pandemic. Data are from } 30,750 \text { survey responses collected from July } \\
2020 \text { to March } 2021 \text { by Inc-Query and QuestionPro. We exclude workers who have "no employer" in the } \\
\text { employer plans question and impute zero planned WFH days to respondents who claim to have received no clear } \\
\text { indication from their employer. We re-weight raw responses to match the share of working age respondents in the } \\
2010-2019 \text { CPS in a given \{age x sex x education x earnings\} cell. }\end{array}$} \\
\hline
\end{tabular}


Table A.8 Vaccine concerns

Percent of respondents voicing concerns about vaccine safety, effectiveness, or take-up

Mean

(SE)

Percent of respondents voicing concerns about

vaccine safety, effectiveness, or take-up

Mean

(SE)

\begin{tabular}{lcc}
\hline Overall & 84.3 & $(0.6)$ \\
\hline Women & & \\
Men & 86.2 & $(0.7)$ \\
\hline
\end{tabular}

Age 20 to 29

81.1

Age 30 to 39

81.3

Age 40 to 49

Age 50 to 64

86.1
80.9
85.8
84.4
86.3

Less than high school

High school

1 to 3 years of college

4year college degree

Graduate degree
(1.4)

87.1

86.4

(1.1)

86.1

$(5.9)$

$(5.9)$
$(1.6)$
$(1.1)$
$(1.0)$
$(1.0)$

Ann. Earnings of $\$ 20$ to $\$ 50 \mathrm{~K}$

84.8

(1.0)

Ann. Earnings of $\$ 50$ to $\$ 100 \mathrm{~K}$

83.8

(1.0)

Ann. Earnings of $\$ 100$ to $\$ 150 \mathrm{~K}$

82.9

Ann. Earnings over $\$ 150 \mathrm{~K}$

83.0

(1.4)

Goods-producing sectors

78.0

(1.5)

Service sectors

85.3

(1.8)

No children

84.9

$(0.6)$

Living with children under 18

83.4

$(0.8)$

Red(Renublican-leanino) state

Red (Republican-leaning) state

83.5 $(0.8)$

84.4

Blue (Democratic-leaning) state
$(0.8)$

$(0.7)$

Notes: This table reports the percent of respondents concerned about vaccine effectiveness, safety, or take-up, among those who would not "completely" return to pre-COVID activities in the event a vaccine is discovered and made widely available. Data are from 7,500 survey responses collected in September, October, and November 2020 by Inc-Query and QuestionPro. Each wave collected 2,500 responses, but we only asked this question if the respondent stated they would not return "completely" to pre-COVID activities in the event a vaccine was discovered and made widely available. We re-weight raw responses to match the share of working age respondents in the 2010-2019 CPS in a given \{age x sex x education $\mathrm{x}$ earnings\} cell. 


\section{Table A.9 Efficiency of WFH vs. working on business premises}

Efficiency while WFH during COVID relative to business premises before COVID, \% difference

\section{Overall}

\section{(ative to business}

Orerall

Women
Men

Age 20 to 29

Age 30 to 39

Age 40 to 49

Age 50 to 64

Less than high school

High school

1 to 3 years of college

4year college degree

Graduate degree

\section{Efficiency while WFH during COVID relative}

to business premises before COVID, \%

Mean (SE) difference

$4.5 \quad(0.1)$

Notes: This table estimates the difference in efficiency while working from home during COVID relative to working on business premises before COVID, among respondents working from home at some point during COVID. Data are from 30,750 survey responses collected from July 2020 to March 2021 by Inc-Query and QuestionPro. We re-weight raw responses to match the share of working age respondents in the 2010-2019 CPS in a given \{age $\mathrm{x}$ sex $\mathrm{x}$ education $\mathrm{x}$ earnings $\}$ cell.
Mean

(SE)

\begin{tabular}{lcc} 
difference & Mean & (SE) \\
\hline & & \\
\hline Ann. Earnings of $\$ 20$ to $\$ 50 \mathrm{~K}$ & & \\
Ann. Earnings of $\$ 50$ to $\$ 100 \mathrm{~K}$ & 2.9 & $(0.3)$ \\
Ann. Earnings of $\$ 100$ to $\$ 150 \mathrm{~K}$ & 4.8 & $(0.2)$ \\
Ann. Earnings over $\$ 150 \mathrm{~K}$ & 7.8 & $(0.3)$ \\
\hline & 10.5 & $(0.3)$ \\
\hline Goods-producing sectors & & \\
Service sectors & 4.7 & $(0.3)$ \\
\hline No children & 4.5 & $(0.1)$ \\
\hline Living with children under 18 & 3.3 & $(0.2)$ \\
\hline Red (Republican-leaning) state & 5.7 & $(0.2)$ \\
\hline Blue (Democratic-leaning) state & & \\
\hline
\end{tabular}

rence

$3.7 \quad(0.2)$

$5.2 \quad(0.2)$

$\begin{array}{ll}4.9 & (0.3) \\ 6.0 & (0.2) \\ 4.7 & (0.3)\end{array}$

$2.5 \quad(0.3)$

1.7

3.1

4.0

4.7

6.4

$(1.8)$
$(0.4)$
$(0.3)$
$(0.2)$
$(0.2)$


Table A.10 What predicts desired and planned WFH post-COVID?

\section{a. Worker desired WFH}

\begin{tabular}{|c|c|c|c|c|c|c|c|}
\hline \multirow[b]{2}{*}{ Dependent Variable } & (1) & (2) & (3) & (4) & (5) & (6) & (7) \\
\hline & \multicolumn{7}{|c|}{ Worker Desired WFH Days, Post-COVID (\%) } \\
\hline Years of education & $\begin{array}{c}3.53 * * * \\
(0.48)\end{array}$ & $\begin{array}{c}3.23 * * * \\
(0.50)\end{array}$ & $\begin{array}{c}2.64 * * * \\
(0.49)\end{array}$ & $\begin{array}{c}2.63 * * * \\
(0.49)\end{array}$ & $\begin{array}{c}2.55 * * * \\
(0.49)\end{array}$ & $\begin{array}{c}2.27 * * * \\
(0.48)\end{array}$ & $\begin{array}{c}1.82 * * * \\
(0.49)\end{array}$ \\
\hline $\log ($ Earnings $)$ & & $\begin{array}{c}1.00 * * \\
(0.43)\end{array}$ & $\begin{array}{c}1.74 * * * \\
(0.46)\end{array}$ & $\begin{array}{c}1.72 * * * \\
(0.46)\end{array}$ & $\begin{array}{c}1.65 * * * \\
(0.46)\end{array}$ & $\begin{array}{c}2.50 * * * \\
(0.46)\end{array}$ & $\begin{array}{c}1.75 * * * \\
(0.46)\end{array}$ \\
\hline 1(Male) & & & $\begin{array}{c}-5.25 * * * \\
(1.04)\end{array}$ & $\begin{array}{c}-5.26^{* * *} \\
(1.04)\end{array}$ & $\begin{array}{c}-5.33 * * * \\
(1.04)\end{array}$ & $\begin{array}{c}-5.80 * * * \\
(1.03)\end{array}$ & $\begin{array}{c}-6.15 * * * \\
(1.06)\end{array}$ \\
\hline 1(Lives with children under 18 ) & & & $\begin{array}{c}2.55 * * * \\
(0.89)\end{array}$ & $\begin{array}{c}2.56 * * * \\
(0.89)\end{array}$ & $\begin{array}{c}2.55 * * * \\
(0.89)\end{array}$ & $\begin{array}{c}0.14 \\
(0.93)\end{array}$ & $\begin{array}{c}0.47 \\
(0.92)\end{array}$ \\
\hline 1(Male) x 1(Lives with children under 18) & & & $\begin{array}{c}-0.81 \\
(1.45)\end{array}$ & $\begin{array}{c}-0.83 \\
(1.45)\end{array}$ & $\begin{array}{c}-0.85 \\
(1.45)\end{array}$ & $\begin{array}{l}-0.80 \\
(1.44)\end{array}$ & $\begin{array}{l}-1.68 \\
(1.42)\end{array}$ \\
\hline Biden vote share (state of residence) & & & & $\begin{array}{c}0.15 \\
(0.40)\end{array}$ & $\begin{array}{c}0.12 \\
(0.40)\end{array}$ & $\begin{array}{c}0.03 \\
(0.39)\end{array}$ & $\begin{array}{l}-0.04 \\
(0.38)\end{array}$ \\
\hline Internet quality & & & & & $\begin{array}{c}1.30 * * * \\
(0.50)\end{array}$ & $\begin{array}{l}1.24 * * \\
(0.49)\end{array}$ & $\begin{array}{l}1.05 * * \\
(0.49)\end{array}$ \\
\hline Survey wave fixed effects & $\mathrm{Y}$ & $\mathrm{Y}$ & $\mathrm{Y}$ & $\mathrm{Y}$ & $\mathrm{Y}$ & $\mathrm{Y}$ & $\mathrm{Y}$ \\
\hline Age bin fixed effects & & & & & & $\mathrm{Y}$ & $\begin{array}{l}\mathrm{Y} \\
\mathrm{Y}\end{array}$ \\
\hline Dependent variable mean & 46.34 & 46.34 & 46.34 & 46.34 & 46.34 & 46.34 & 46.34 \\
\hline Observations & 25,056 & 25,056 & 25,056 & 25,056 & 25,056 & 25,056 & 25,056 \\
\hline (l) & 0.01 & 0.01 & 0.02 & 0.02 & 0.02 & 0.03 & 0.04 \\
\hline
\end{tabular}




\section{b. Employer planned WFH}

\section{Dependent Variable}

Years of education

$\log ($ Earnings $)$

1(Male)

1(Lives with children under 18)

1(Male) x 1(Lives with children under 18)

Biden vote share (state of residence)

Internet quality

Survey wave fixed effects

Age bin fixed effects

Industry Fixed Effects

Dependent variable mean

Observations

21.35

R-squared

0.03

(2)

(3)

(4)

(5)

(6)

(7) Employer Planned WFH Days, Post-COVID (\%)

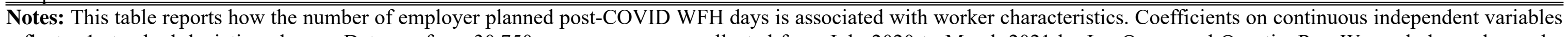

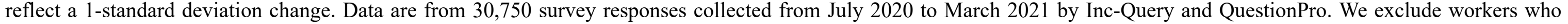

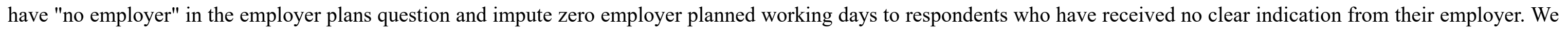
re-weight raw responses to match the share of working age respondents in the 2010-2019 CPS in a given \{age x sex x education $\mathrm{x}$ earnings cell. 


\section{Table A.11 What predicts self-assessed efficiency while WFH during COVID?}

\begin{tabular}{|c|c|c|c|c|c|c|c|}
\hline \multirow[b]{2}{*}{ Dependent Variable } & (1) & (2) & (3) & (4) & (5) & (6) & (7) \\
\hline & \multicolumn{7}{|c|}{ Relative efficiency of WFH during COVID vs. on business premises before COVID (\%) } \\
\hline Years of education & $\begin{array}{c}1.29 * * * \\
(0.25)\end{array}$ & $\begin{array}{c}0.64 * * \\
(0.27)\end{array}$ & $\begin{array}{c}0.68 * * \\
(0.26)\end{array}$ & $\begin{array}{c}0.68 * * \\
(0.26)\end{array}$ & $\begin{array}{c}0.57 * * \\
(0.26)\end{array}$ & $\begin{array}{c}0.56 * * \\
(0.26)\end{array}$ & $\begin{array}{c}0.70 * * \\
(0.28)\end{array}$ \\
\hline $\log ($ Earnings $)$ & & $\begin{array}{c}2.18 * * * \\
(0.22)\end{array}$ & $\begin{array}{c}1.93 * * * \\
(0.23)\end{array}$ & $\begin{array}{c}1.93 * * * \\
(0.23)\end{array}$ & $\begin{array}{c}1.78 * * * \\
(0.23)\end{array}$ & $\begin{array}{c}2.22 * * * \\
(0.23)\end{array}$ & $\begin{array}{c}1.88 * * * \\
(0.23)\end{array}$ \\
\hline 1(Male) & & & $\begin{array}{c}-0.20 \\
(0.56)\end{array}$ & $\begin{array}{c}-0.20 \\
(0.56)\end{array}$ & $\begin{array}{c}-0.36 \\
(0.56)\end{array}$ & $\begin{array}{l}-0.57 \\
(0.55)\end{array}$ & $\begin{array}{c}-0.87 \\
(0.56)\end{array}$ \\
\hline 1(Lives with children under 18) & & & $\begin{array}{l}1.19 * * \\
(0.52)\end{array}$ & $\begin{array}{c}1.19 * * \\
(0.52)\end{array}$ & $\begin{array}{l}1.24 * * \\
(0.51)\end{array}$ & $\begin{array}{c}0.46 \\
(0.53)\end{array}$ & $\begin{array}{c}0.51 \\
(0.53)\end{array}$ \\
\hline 1(Male) x 1(Lives with children under 18) & & & $\begin{array}{l}1.51 * \\
(0.78)\end{array}$ & $\begin{array}{l}1.52 * \\
(0.78)\end{array}$ & $\begin{array}{l}1.53 * * \\
(0.77)\end{array}$ & $\begin{array}{c}1.66^{* * *} \\
(0.76)\end{array}$ & $\begin{array}{c}1.18 \\
(0.76)\end{array}$ \\
\hline Biden vote share (state of residence) & & & & $\begin{array}{l}-0.03 \\
(0.18)\end{array}$ & $\begin{array}{c}-0.09 \\
(0.18)\end{array}$ & $\begin{array}{c}-0.15 \\
(0.18)\end{array}$ & $\begin{array}{c}-0.17 \\
(0.18)\end{array}$ \\
\hline Internet quality & & & & & $\begin{array}{c}2.63 * * * \\
(0.28)\end{array}$ & $\begin{array}{c}2.63 * * * \\
(0.28)\end{array}$ & $\begin{array}{c}2.50 * * * \\
(0.28)\end{array}$ \\
\hline $\begin{array}{l}\text { Survey wave fixed effects } \\
\text { Age bin fixed effects } \\
\text { Industry Fixed Effects }\end{array}$ & Y & $\mathrm{Y}$ & Y & $\mathrm{Y}$ & Y & $\begin{array}{l}\mathrm{Y} \\
\mathrm{Y}\end{array}$ & $\begin{array}{l}\mathrm{Y} \\
\mathrm{Y} \\
\mathrm{Y}\end{array}$ \\
\hline $\begin{array}{l}\text { Dependent variable mean } \\
\text { Observations } \\
\text { R-squared } \\
\end{array}$ & $\begin{array}{c}4.90 \\
15,947 \\
0.01 \\
\end{array}$ & $\begin{array}{c}4.90 \\
15,947 \\
0.02 \\
\end{array}$ & $\begin{array}{c}4.90 \\
15,947 \\
0.02 \\
\end{array}$ & $\begin{array}{c}4.90 \\
15,947 \\
0.02 \\
\end{array}$ & $\begin{array}{c}4.90 \\
15,947 \\
0.04 \\
\end{array}$ & $\begin{array}{c}4.90 \\
15,947 \\
0.05 \\
\end{array}$ & $\begin{array}{c}4.90 \\
15,947 \\
0.06 \\
\end{array}$ \\
\hline
\end{tabular}

R-squared

$0.01-0.02$

0.02

0.02

0.04

0.05

0.06

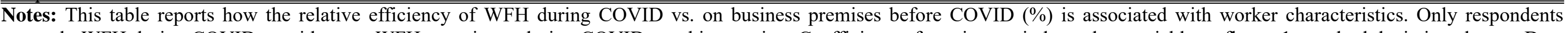

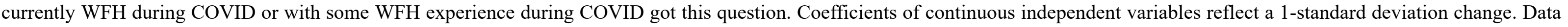

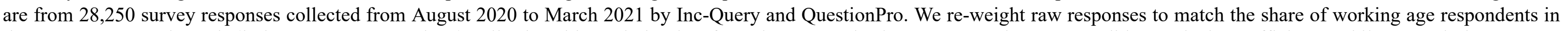

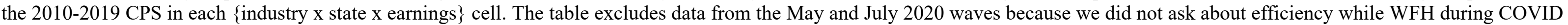
in May, and the July version of the question provided response options that were not symmetric about zero. 
CENTRE FOR ECONOMIC PERFORMANCE

Recent Discussion Papers

\begin{tabular}{|c|c|c|}
\hline 1789 & $\begin{array}{l}\text { Scott R. Baker } \\
\text { Nicholas Bloom } \\
\text { Steven J. Davis } \\
\text { Marco Sammon }\end{array}$ & What triggers stock market jumps? \\
\hline 1788 & $\begin{array}{l}\text { Nicolas Bloom } \\
\text { Robert S. Fletcher } \\
\text { Ethan Yeh }\end{array}$ & The impact of Covid-19 on US firms \\
\hline 1787 & $\begin{array}{l}\text { Philippe Aghion } \\
\text { Antonin Bergeaud } \\
\text { Matthieu Lequien } \\
\text { Marc J. Melitz } \\
\text { Thomas Zuber }\end{array}$ & $\begin{array}{l}\text { Opposing firm-level responses to the China } \\
\text { shock: horizontal competition versus vertical } \\
\text { relationships }\end{array}$ \\
\hline 1786 & $\begin{array}{l}\text { Elsa Leromain } \\
\text { Gonzague Vannoorenberghe }\end{array}$ & $\begin{array}{l}\text { Voting under threat: evidence from the } 2020 \\
\text { French local elections }\end{array}$ \\
\hline 1785 & $\begin{array}{l}\text { Benny Kleinman } \\
\text { Ernest Liu } \\
\text { Stephen J. Redding }\end{array}$ & Dynamic spatial general equilibrium \\
\hline 1784 & $\begin{array}{l}\text { Antonin Bergeaud } \\
\text { Clément Malgouyres } \\
\text { Clément Mazet-Sonilhac } \\
\text { Sara Signorelli }\end{array}$ & $\begin{array}{l}\text { Technological change and domestic } \\
\text { outsourcing }\end{array}$ \\
\hline 1783 & $\begin{array}{l}\text { Facundo Albornoz } \\
\text { Irene Brambilla } \\
\text { Emanuel Ornelas }\end{array}$ & Firm export responses to tariff hikes \\
\hline 1782 & $\begin{array}{l}\text { Gabriel M. Ahlfeldt } \\
\text { Stephan Heblich } \\
\text { Tobias Seidel }\end{array}$ & $\begin{array}{l}\text { Micro-geographic property price and rent } \\
\text { indices }\end{array}$ \\
\hline 1781 & $\begin{array}{l}\text { Ria Ivandić } \\
\text { Tom Kirchmaier } \\
\text { Neus Torres-Blas }\end{array}$ & Football, alcohol and domestic abuse \\
\hline 1780 & $\begin{array}{l}\text { Monica Langella } \\
\text { Alan Manning }\end{array}$ & The measure of monopsony \\
\hline
\end{tabular}




\begin{tabular}{|c|c|c|}
\hline 1779 & $\begin{array}{l}\text { Holger Breinlich } \\
\text { Elsa Leromain } \\
\text { Dennis Novy } \\
\text { Thomas Sampson }\end{array}$ & $\begin{array}{l}\text { Import liberalization as export destruction? } \\
\text { Evidence from the United States }\end{array}$ \\
\hline 1778 & $\begin{array}{l}\text { Andrew E. Clark } \\
\text { Conchita D’Ambrosio } \\
\text { Anthony Lepinteur }\end{array}$ & $\begin{array}{l}\text { Marriage as insurance: job protection and job } \\
\text { insecurity in France }\end{array}$ \\
\hline 1777 & $\begin{array}{l}\text { Marc J. Melitz } \\
\text { Stephen J. Redding }\end{array}$ & Trade and innovation \\
\hline 1776 & $\begin{array}{l}\text { Holger Breinlich } \\
\text { Valentina Corradi } \\
\text { Nadia Rocha } \\
\text { Michele Ruta } \\
\text { J.M.C. Santos Silva } \\
\text { Tom Zylkin }\end{array}$ & $\begin{array}{l}\text { Machine learning in international trade } \\
\text { research - evaluating the impact of trade } \\
\text { agreements }\end{array}$ \\
\hline 1775 & $\begin{array}{l}\text { Giuseppe Berlingieri } \\
\text { Luca Marcolin } \\
\text { Emanuel Ornelas }\end{array}$ & Service offshoring and export experience \\
\hline 1774 & $\begin{array}{l}\text { Facundo Albornoz } \\
\text { Héctor F. Calvo Pardo } \\
\text { Gregory Corcos } \\
\text { Emanuel Ornelas }\end{array}$ & $\begin{array}{l}\text { Sequential exporting across countries and } \\
\text { products }\end{array}$ \\
\hline 1773 & $\begin{array}{l}\text { Nicholas Stern } \\
\text { Anna Valero }\end{array}$ & $\begin{array}{l}\text { Innovation, growth and the transition to net- } \\
\text { zero emissions }\end{array}$ \\
\hline 1772 & $\begin{array}{l}\text { Paul Dolan } \\
\text { Christian Krekel } \\
\text { Ganga Shreedhar } \\
\text { Helen Lee } \\
\text { Claire Marshall } \\
\text { Allison Smith }\end{array}$ & $\begin{array}{l}\text { Happy to help: The welfare effects of a } \\
\text { nationwide micro-volunteering programme }\end{array}$ \\
\hline 1771 & $\begin{array}{l}\text { Xuepeng Liu } \\
\text { Emanuel Ornelas } \\
\text { Huimin Shi }\end{array}$ & The trade impact of the Covid-19 pandemic \\
\hline
\end{tabular}

The Centre for Economic Performance Publications Unit

Tel: +44 (0)207955 7673 Email info@cep.lse.ac.uk

Website: http://cep.lse.ac.uk Twitter: @CEP_LSE 